\title{
PROYECTO DE ATENCIÓN A VÍCTIMAS DE VIOLENCIA SEXUAL EN EL CONSULTORIO JURÍDICO DE LA PONTIFICIA UNIVERSIDAD JAVERIANA*
}

\section{PROJECT FOR THE ASSISTANCE OF VICTIMS OF SEXUAL VIOLENCE IN THE LEGAL CLINIC OF PONTIFICIA UNIVERSIDAD JAVERIANA}

\author{
Julio Andrés Sampedro-Arrubla \\ Vanessa Suelt-Cock \\ Consuelo Quiñones-Camargo \\ Javier D. Coronado-Díaz**
}

Fecha de recepción: 20 de enero de 2014

Fecha de aceptación: 18 de marzo de 2014

Disponible en línea: 30 de Julio de 2014

\section{Para citar este artículo/To cite this article}

\author{
Sampedro-Arrubla, Julio Andrés; Suelt-Cock, Vanessa; Quiñones- \\ Camargo, Consuelo \& Coronado-Díaz, Javier D., Proyecto de Atención \\ a Víctimas de Violencia Sexual en el Consultorio Jurídico de la Pontificia \\ Universidad Javeriana, 129 Vniversitas, 275-315 (2014). http://dx.doi. \\ org/10.11144/Javeriana.VJ129.pavv \\ doi:10.11144/Javeriana.VJ129.pavv
}

* El siguiente artículo presenta los hallazgos de la investigación sociojurídica adelantada por las Facultades de Ciencias Jurídicas y Psicología de la Pontificia Universidad Javeriana, por intermedio de sus grupos de investigación de Estudios en Derecho Público, y Psicología Jurídica: Retos y Perspectivas, de la mano del programa para apoyar el doctorado de la Facultad de Ciencias Jurídicas.

** Los investigadores acá citados hacen parte del grupo de investigación Estudios en Derecho Público. Los investigadores Fernando Díaz-Colorado y Pilar García-Padilla, pertenecientes al grupo de investigación Psicología Jurídica: Retos y Perspectivas de la Facultad de Psicología, presentarán los resultados psicológicos de la investigación en otra publicación especializada. Es oportuno agradecer la colaboración de la doctora Carolina Moreno (en especial, en la primera parte de esta investigación), la de los estudiantes que, desde el Consultorio Jurídico, prestaron su colaboración; la de los profesionales de las diferentes entidades que forman parte de la Ruta de Atención y que contribuyeron al desarrollo del Proyecto; y, de manera especial, agradecemos a las víctimas (directas e indirectas) que enriquecieron la investigación con sus experiencias y percepciones. 


\section{RESUMEN}

Este artículo tiene como propósito presentar el informe final de investigación del Proyecto de Atención a Víctimas de Violencia Sexual, que contiene los criterios jurídicos de un programa de atención a víctimas de delitos sexuales en el Consultorio Jurídico de la Pontificia Universidad Javeriana, enmarcados en los principios éticos, jurídicos y los derechos de las víctimas establecidos por la normatividad internacional y nacional.

Palabras clave: víctimas de delitos sexuales; revictimización; criterios de atención a víctimas de delitos sexuales 


\section{ABSTRACT}

This article aims to present the final report of the research project for the assistance of victims of Sexual Violence, which contains the legal criteria of a program of assistance to victims in the Legal Clinic of the Pontificia Universidad Javeriana, framed in the ethical and legal principles, as well as in the victims' rights established by international and national regulations.

Key words: victims of sexual offenses; revictimization; criteria for the care of victims of sexual crimes

\section{SUMARIO}

INTRODUCCIÓN.- I. VÍCTIMA Y VICTIMIZACIÓN: HITOS CONCEPTUALES DEL PROYECTO.- II. ESTÁNDARES JURÍDICOS PARA LA ATENCIÓN A VÍCTIMAS DE DELITOS SEXUAles.- A. La garantía de los derechos de las víctimas en Colombia.- B. Esfuerzos específicos del Estado colombiano para la protección de víctimas de delitos sexuales.- C. El interés superior de los menores en los procesos de atención a víctimas de delitos sexuales. - III. LAS ACTIVIDADES DESARROLLADAS EN El PROYeCto.- IV. Problemáticas JuRídicAS DETECTADAS EN LA ATENCIÓN A LAS VÍctimas DE DELITOS SEXUALES.- $A$. Dificultades relacionadas con la preparación y aptitudes del personal que interviene en el proceso de atención.- B. Dificultades relacionadas con las instalaciones utilizadas para la atención a víctimas.- C. Dificultades relacionadas con la implementación de politicas públicas en la materia.- D. Dificultades relacionadas con los servicios prestados a la víctima.- E. Dificultades relacionadas con la evocación de los hechos.- V. FUNDAMENTOS Y CRITERIOS PARA LA ATENCIÓN JuRídicA de víctimas de DElitos SEXuAles.- ConClusión.- Bibliografía. 


\section{INTRODUCCIÓN}

En 2011, las Facultades de Ciencias Jurídicas y Psicología de la Pontificia Universidad Javeriana, con sus grupos de investigación de Estudios en Derecho Público, y Psicología Jurídica: Retos y Perspectivas, respectivamente, decidieron contribuir con la labor del Consultorio Jurídico, en cuanto a la atención a víctimas de delitos sexuales. En ese sentido, de la mano de la Universidad, el programa para apoyar el doctorado de la Facultad de Ciencias Jurídicas llevó a cabo un análisis victimológico sobre las actividades de las entidades que forman parte de la ruta de atención a este tipo de víctimas y específicamente del Consultorio Jurídico, que presta atención a niños y niñas víctimas.

Así, pues, los investigadores asociados buscaron identificar los criterios que deberían orientar la atención a víctimas de delitos sexuales, a partir de las directrices nacionales e internacionales sobre los derechos de las víctimas y sobre la atenuación de los efectos victimizantes provenientes de la judicialización de este tipo de delitos. Lo anterior, al tiempo que se realizaba una revisión crítica de los procesos de atención administrativos y judiciales utilizados actualmente.

A continuación, para describir los resultados del Proyecto, en primer lugar, se abordarán dos conceptos vitales para su desarro1lo. En segundo lugar, se hará alusión a los estándares existentes en Colombia para la atención a víctimas de delitos sexuales y, de manera específica, el artículo ahondará en las fuentes jurídicas que soportan el compromiso estatal en la materia y en el interés superior del menor como principio rector de la atención. En tercer lugar, se describirán las actividades de investigación adelantadas en el Proyecto y en especial las problemáticas en la ruta de atención que fueron detectadas gracias a ellas. Por último, se identificarán los fundamentos que deben orientar la atención a víctimas de delitos sexuales y los criterios para el desarrollo de esta labor en el Consultorio Jurídico de la Pontificia Universidad Javeriana. 


\section{Víctima y victimización: hitos conceptuales del Proyecto}

Toda vez que el Proyecto buscó ahondar en las expectativas y necesidades de las víctimas, al tiempo que en las problemáticas relacionadas con la atención a víctimas de delitos sexuales, su trasfondo teórico-básico se encuentra en los conceptos de víctima y victimización. En relación con el primer concepto, el artículo 132 de la Ley 906 de 2004, Código de Procedimiento Penal vigente, definía: "Se entiende por víctimas, para efectos de este código, las personas naturales o jurídicas y demás sujetos de derechos que individual o colectivamente hayan sufrido algún daño directo como consecuencia del injusto". Sin embargo, esa definición fue modificada por la Corte Constitucional en la Sentencia C-516 de 2007, que excluyó del ordenamiento jurídico la palabra "directo". Lo anterior, pues la Corte Constitucional recordó que la determinación de la calidad de víctima debía partir de la existencia de un daño “...real, cierto y concreto...”; con independencia de los juicios que pudieran realizarse sobre la causalidad del daño.

Partiendo de esta noción, el Proyecto entendió que, en Colombia, podría ser considerada como víctima de delito sexual, toda persona que haya sufrido un daño real, cierto y concreto, con ocasión de las conductas previstas en el Título IV del Libro II del Código Penal, que contempla las infracciones contra la libertad, integridad y formación sexuales.

En cuanto a la victimización, de manera general, este concepto puede ser entendido como el proceso por el cual una persona sufre las consecuencias de experimentar un hecho traumático o la ocurrencia de un delito: consecuencias directas, indirectas y las que son posteriores al hecho (como las consecuencias físicas, psicológicas, jurídicas, judiciales, sociales, culturales, económicas) ${ }^{1}$. Sin embargo, para examinar los alcances del concepto, la teoría victimológica suele acudir a tres categorías distintas: victimización primaria, secundaria y terciaria ${ }^{2}$.

\footnotetext{
1 Claudia Capella-Sepúlveda \& Jennifer Miranda, Diseño, implementación y evaluación piloto de una intervención psicoterapéutica grupal para niñas víctimas de abuso sexual, memoria para optar al título de psicólogo, Universidad de Chile, Santiago de Chile (2003).

2 Fernando Díaz-Colorado, Psicología y Ley. Psicología jurídica, forense, criminológica y victimología, Psicom Editores, Bogotá (2011).
} 
La victimización primaria hace referencia a los daños que sufre la víctima, con ocasión de la comisión de un delito ${ }^{3}$. La victimización secundaria tiene dos acepciones, que resultan complementarias entre sí: la primera, más genérica, se refiere a las “... distintas instancias sociales e instituciones, que se relacionan con la víctima después de ocurrido el delito, incluidos los medios de comunicación y el sistema familiar, infligiendo a la víctima un daño adicional..."4; la segunda, más restringida, hace referencia a "...las consecuencias negativas asociadas con el paso de la víctima por el sistema de justicia penal..." . Finalmente, la victimización terciaria hace referencia a los procesos sociales y familiares que le siguen al hecho delictivo (v. gr. rechazo o incomprensión por parte del entorno de la víctima $)^{6}$.

\section{ESTÁNDARES JURÍdICOS PARA LA ATENCIÓN A VÍCTIMAS DE DELITOS SEXUALES}

\section{A. La garantía de los derechos de las victimas en Colombia}

Con la Sentencia C-228 del 3 de abril de 2002, la Corte Constitucional marcó el hito en el proceso de reconocimiento de los derechos fundamentales de las víctimas en Colombia ${ }^{7}$, cuando advirtió que el proceso penal debía ser un escenario para que los perjudicados por el delito consiguieran la realización de tres garantías autónomas: i) el derecho a la verdad, entendido como la facultad de conocer lo realmente ocurrido; ii) el derecho a la justicia, definido como el

3 Fernando Díaz-Colorado, Psicología y Ley. Psicología jurídica, forense, criminológica y victimología, Psicom Editores, Bogotá (2011).

4 Mayra Miranda-Herrera, Victimización secundaria en adolescentes víctimas de delitos sexuales en su paso por el sistema procesal penal en Chile: una aproximación narrativa, 12, Santiago de Chile: Universidad de Chile (2012). Disponible en: http://www.tesis.uchile.cl/tesis/uchile/2012/ cs-miranda_m/pdfAmont/cs-miranda_m.pdf

5 Mayra Miranda-Herrera, Victimización secundaria en adolescentes víctimas de delitos sexuales en su paso por el sistema procesal penal en Chile: una aproximación narrativa, 58, Santiago de Chile: Universidad de Chile (2012). Disponible en: http://www.tesis.uchile.cl/tesis/uchile/2012/ cs-miranda_m/pdfAmont/cs-miranda_m.pdf

6 Fernando Díaz-Colorado, Psicología y Ley. Psicología jurídica, forense, criminológica y victimología, Psicom Editores, Bogotá (2011).

7 Corte Constitucional, Sentencia C-228 de 2002, 3 de abril de 2002. Magistrados ponentes: Manuel José Cepeda-Espinosa \& Eduardo Montealegre-Lynett. Disponible en: http://corteconstitucional.gov.co/relatoria/2002/C-228-02.htm 
derecho a que no haya impunidad; y iii) el derecho a la reparación, relacionado por la Corte con la compensación económica. Para sustentar el reconocimiento y la garantía de las mentadas prerrogativas, el juez constitucional acudió al contenido de los artículos 1, 2, 15, 21, 229 y 250 de la Carta. Además, el Alto Tribunal sostuvo que la garantía de los derechos mencionados se desprendía de los estándares internacionales ratificados por Colombia (en particular, de la garantía de tutela judicial efectiva consagrada en los instrumentos internacionales ${ }^{8}$ ). Además, la Corte también explicó su razonamiento en lo que denominó como una "tendencia" del derecho internacional'.

Con posterioridad al referido fallo, se presentaron dos situaciones normativas que le han permitido a la Corte retomar y sofisticar los planteamientos descritos sobre los derechos de las víctimas, en ejercicio del control de constitucionalidad: la introducción del nuevo sistema de enjuiciamiento criminal y la puesta en marcha del procedimiento especial para la reincorporación de miembros de grupos armados organizados al margen de la ley.

Respecto del primer suceso, cabe recordar que, en diciembre de 2002, por medio del Acto legislativo 03, el Congreso introdujo las bases constitucionales de un sistema procesal de tendencia acusatoria, que fue posteriormente desarrollado mediante la Ley 906 de 2004. En sus inicios, el despliegue legal buscó instaurarse como una apuesta preferencial por las víctimas, como se puede evidenciar en algunas de las disposiciones vigentes (artículos 11, 22, 102 a 108 y 132 a 137). No obstante lo anterior, el propósito inicial fue opacado por los objetivos de algunos actores de la reforma ${ }^{10} \mathrm{y}$

8 Específicamente, la Corte se refirió a la Declaración Americana de Derechos y Deberes del Hombre (artículo XVIII), la Declaración Universal de Derechos Humanos (artículo 8), la Convención Americana de Derechos Humanos (artículo 25), y el Pacto Internacional de Derechos Civiles y Políticos (artículo 2.1). Corte Constitucional, Sentencia C-228 de 2002, 3 de abril de 2002. Magistrados ponentes: Manuel José Cepeda-Espinosa \& Eduardo Montealegre-Lynett. Disponible en: http://corteconstitucional.gov.co/relatoria/2002/C-228-02.htm

9 Esta percepción fue soportada en la Declaración sobre los Principios Fundamentales de Justicia para las Víctimas de Delitos y del Abuso de Poder, de la Asamblea General de Naciones Unidas, y en algunas disposiciones del Protocolo I adicional a los Convenios de Ginebra de 1949 y del Estatuto de la Corte Penal Internacional. Corte Constitucional, Sentencia C-228 de 2002, 3 de abril de 2002. Magistrados ponentes: Manuel José Cepeda-Espinosa \& Eduardo Montealegre-Lynett. Disponible en: http://corteconstitucional.gov.co/relatoria/2002/C-228-02. htm

10 Julio Andrés Sampedro-Arrubla, Las víctimas y el sistema penal, Grupo Editorial Ibáñez, Bogotá, $72-76$ (2010). 
el juez constitucional optó por reivindicar las siguientes facultades de la víctima en el proceso penal:

- Ser enterada del archivo de la investigación y manifestar su inconformidad frente a esta determinación (Sentencia C-1154 de 2005).

- Conocer la inadmisión de la denuncia y oponerse a esta determinación (Sentencia C-1177 de 2005).

- Intervenir en los preacuerdos y negociaciones del investigado con la Fiscalía, para obtener la garantía de los derechos a la verdad, la justicia y la reparación integral (Sentencia C-516 de 2007).

- Tener una representación técnica durante el proceso (Sentencia C-516 de 2007).

- Obtener, desde el momento en que entra en contacto con las autoridades, información sobre los derechos que el orden jurídico establece para garantizar sus intereses en el proceso penal, y acerca de las circunstancias en que se cometió el delito (Sentencia C-454 de 2006).

- Realizar solicitudes probatorias en la audiencia preparatoria, en igualdad de condiciones que la defensa y la fiscalía (Sentencia C-454 de 2006).

- Solicitar pruebas anticipadas ante el juez de control de garantías (Sentencia C-209 de 2007).

- Intervenir durante la audiencia de formulación de imputación (Sentencia C-209 de 2007).

- Solicitar medidas de aseguramiento y de protección ante el juez competente (Sentencia C-209 de 2007).

- Controvertir la decisión de dar aplicación al principio de oportunidad (Sentencia C-209 de 2007).

- Allegar o solicitar elementos materiales probatorios y evidencia física para oponerse a la petición de preclusión del fiscal (Sentencia C-209 de 2007).

- Intervenir en la audiencia de formulación de acusación para formular observaciones al escrito de acusación, manifestarse sobre posibles causales de incompetencia, recusaciones, impedimentos o nulidades; o solicitar el descubrimiento de un elemento material probatorio específico (Sentencia C-209 de 2007). 
- Ser escuchado por el fiscal durante el juicio oral, para conseguir una debida representación de sus intereses (Sentencia C-209 de 2007).

- Intervenir en la audiencia de individualización de pena y sentencia, para referirse a las condiciones individuales, familiares, sociales, modo de vivir y antecedentes de todo orden del culpable (C-250 de 2011).

- Solicitar la adición de la sentencia o de la decisión con efectos equivalentes, que omita un pronunciamiento definitivo sobre los bienes afectados con fines de comiso, con el fin de obtener el respectivo pronunciamiento (C-782 de 2012).

- Solicitar al Juez de Control de Garantías la suspensión de los registros obtenidos de manera fraudulenta (C-839 de 2013) ${ }^{11}$.

En cuanto al segundo acontecer normativo que le permitió a la Corte reivindicar los derechos de las víctimas, se recuerda que, mediante la Ley 975 de 2005, conocida como Ley de Justicia y Paz, el Congreso articuló un procedimiento que permite la desmovilización de grupos armados ilegales y que, por lo menos en el texto legal, propugna por las garantías de verdad, justicia y reparación (artículos 4 a 8). En este punto, la intervención del juez constitucional se produjo para garantizar que este cuerpo normativo fuera efectivamente ponderado con los derechos de las víctimas ${ }^{12}$.

11 Corte Constitucional, Sentencia C-1154 de 2005, 15 de noviembre de 2005. Magistrado ponente Manuel José Cepeda-Espinosa. Disponible en: http://www.corteconstitucional.gov.co/ relatoria/2005/c-1154-05.htm. Corte Constitucional, Sentencia C-1177 de 2005, 17 de noviembre de 2005. Magistrado ponente Jaime Córdoba-Triviño. Disponible en: http://www.corteconstitucional.gov.co/relatoria/2005/C-1177-05.htm. Corte Constitucional, Sentencia C-516 de 2007, 11 de julio de 2007. Magistrado ponente Jaime Córdoba-Triviño. Disponible en: http://www. alcaldiabogota.gov.co/sisjur/normas/Norma1.jsp?i=27340. Corte Constitucional, Sentencia C-454 de 2006, 7 de junio de 2006. Magistrado ponente Jaime Córdoba-Triviño. Disponible en: http://www.corteconstitucional.gov.co/relatoria/2006/c-454-06.htm. Corte Constitucional, Sentencia C-209 de 2007, 21 de marzo de 2007. Magistrado ponente Manuel José CepedaEspinosa. Disponible en: http://www.corteconstitucional.gov.co/relatoria/2007/c-209-07. htm. Corte Constitucional, Sentencia C-250 de 2011, 6 de abril de 2011. Magistrado ponente Mauricio González-Cuervo. Disponible en: http://www.corteconstitucional.gov.co/ relatoria/2011/c-250-11.htm. Corte Constitucional, Sentencia C-782 de 2012, 10 de octubre de 2012. Magistrado ponente Luis Ernesto Vargas-Silva. Disponible en: http://www.corteconstitucional.gov.co/relatoria/2012/c-782-12.htm. Corte Constitucional, Sentencia C-839 de 2013, 20 de noviembre de 2013. Magistrado ponente Jorge Ignacio Pretelt-Chaljub. Disponible en: http://www.corteconstitucional.gov.co/relatoria/2013/C-839-13.htm

12 En este punto se puede hacer mención de las sentencias C-370/06, C-575/06 y C-1199/08. Corte Constitucional, Sentencia C-370 de 2006, 18 de mayo de 2006. Magistrados ponentes: Manuel José Cepeda-Espinosa, Jaime Córdoba-Triviño, Rodrigo Escobar-Gil, Marco Gerardo 
Del estudio de las providencias motivadas por los descritos sucesos, se pueden identificar algunas tendencias que evidencian el desarrollo de los derechos de las víctimas en la jurisprudencia constitucional colombiana. En primer lugar, el reconocimiento de los derechos de las víctimas fue soportado en los deberes adquiridos por el Estado colombiano, adicionales a los anticipados por la sentencia C-228 de $2002^{13}$. En segundo lugar, la Corte sostuvo que el respeto por los derechos de las víctimas se instauraba en un límite a la hora de estructurar procedimientos que confieran un tratamiento punitivo más benigno para quienes cesan en la ejecución de actividades delictivas ${ }^{14}$. Finalmente, el juez se preocupó por precisar el contenido de los derechos de las víctimas y, en ese sentido, ha examinado las múltiples subgarantías y obligaciones estatales que se derivan de los postulados de verdad, justicia y reparación.

Ahora, de forma paralela al desarrollo de las víctimas en sentencias dictadas en ejercicio del control de constitucionalidad de las leyes, la Corte Constitucional encontró otro escenario para analizar el alcance de tales derechos y que permite anunciar el carácter

Monroy-Cabra, Álvaro Tafur-Galvis \& Clara Inés Vargas-Hernández. Disponible en: http:// www.corteconstitucional.gov.co/relatoria/2006/c-370-06.htm. Corte Constitucional, Sentencia C-575 de 2006, 25 de julio de 2006. Magistrado ponente Álvaro Tafur-Galvis. Disponible en: http://www.corteconstitucional.gov.co/relatoria/2006/c-575-06.htm. Corte Constitucional, Sentencia C-1199 de 2008, 4 de diciembre de 2008. Magistrado ponente Nilson Pinilla-Pinilla. Disponible en: http://www.corteconstitucional.gov.co/relatoria/2008/c-1199-08.htm

13 Como fuentes de los mentados deberes, la referenciada jurisprudencia menciona la Convención Americana de Derechos Humanos (artículos 1, 2, 8 y 25); Convención contra la Tortura y Otros Tratos o Penas Crueles, Inhumanos o Degradantes; Convención Interamericana para Prevenir y Sancionar la Tortura; Convención Interamericana sobre Desaparición Forzada de Personas; Convención para la Prevención y la Sanción del Delito de Genocidio; el Estatuto de la Corte Penal Internacional y el Conjunto de principios para la protección y la promoción de los derechos humanos mediante la lucha contra la impunidad proclamados por la ONU en 1998. Corte Constitucional, Sentencia C-370 de 2006, 18 de mayo de 2006. Magistrados ponentes: Manuel José Cepeda-Espinosa, Jaime Córdoba-Triviño, Rodrigo Escobar-Gil, Marco Gerardo Monroy-Cabra, Álvaro Tafur-Galvis \& Clara Inés Vargas-Hernández. Disponible en: http://www.corteconstitucional.gov.co/relatoria/2006/c-370-06.htm. Corte Constitucional, Sentencia C-936 de 2010, 23 de noviembre de 2010. Magistrado ponente Luis Ernesto VargasSilva. Disponible en: http://www.corteconstitucional.gov.co/relatoria/2010/c-936-10.htm

14 En ese sentido, por ejemplo, ha sostenido que del contenido mínimo del derecho a la verdad se desprende que este tipo de trámites no pueden ser óbice para que el Estado incumpla su deber de investigar las circunstancias del delito en un tiempo razonable, e igualmente deben garantizar escenarios en los que la víctima pueda conocer las circunstancias de tiempo, modo y lugar en las que los delitos fueron cometidos. Corte Constitucional, Sentencia C-370 de 2006, 18 de mayo de 2006. Magistrados ponentes: Manuel José Cepeda-Espinosa, Jaime Córdoba-Triviño, Rodrigo Escobar-Gil, Marco Gerardo Monroy-Cabra, Álvaro TafurGalvis \& Clara Inés Vargas-Hernández. Disponible en: http://www.corteconstitucional.gov. co/relatoria/2006/c-370-06.htm 
fundamental que adquirieron los derechos a la verdad, la justicia y la reparación en Colombia: los fallos en los que revisa las acciones de tutela resueltas por otros jueces de la república ${ }^{15}$.

Igualmente, la protección de los derechos de las víctimas se convirtió en un factor determinante en las decisiones de otras autoridades. Así pues, otros operadores judiciales empezaron a considerar las garantías de verdad, justicia y reparación, a la hora de aplicar las instituciones jurídicas del proceso penal ${ }^{16}$. De igual manera, las autoridades administrativas, el reconocimiento del derecho a la reparación integral implicó la adopción de programas especiales para responder a las necesidades de las víctimas ${ }^{17}$.

15 Al respecto, pueden ser mencionadas las sentencias T-025/04, T-114/04, T-188/07, T-821/07, T-1135/08, T-520A/09 y T-458/10. Corte Constitucional, Sentencia T-025 de 2004, 22 de enero de 2004. Magistrado ponente Manuel José Cepeda-Espinosa. Disponible en: http://www.corteconstitucional.gov.co/relatoria/2004/T-025-04.htm. Corte Constitucional, Sentencia T-114 de 2004, 12 de febrero de 2004. Magistrado ponente Jaime Córdoba-Triviño. Disponible en: http://www.corteconstitucional.gov.co/relatoria/2004/T-114-04.htm. Corte Constitucional, Sentencia T-188 de 2007, 15 de marzo de 2007. Magistrado ponente Álvaro-Tafur-Galvis. Disponible en: http://www.corteconstitucional.gov.co/relatoria/2007/T-188-07.htm. Corte Constitucional, Sentencia T-821 de 2007, 5 de octubre de 2007. Magistrado ponente Catalina Botero-Marino. Disponible en: http://www.corteconstitucional.gov.co/relatoria/2007/T-821-07. htm. Corte Constitucional, Sentencia T-1135 de 2008, 14 de noviembre de 2007. Magistrado ponente Manuel José Cepeda-Espinosa. Disponible en: http://www.corteconstitucional.gov. co/relatoria/2008/T-1135-08.htm. Corte Constitucional, Sentencia T-520A de 2009, 31 de julio de 2009. Magistrado ponente Mauricio González-Cuervo. Disponible en: http://www. corteconstitucional.gov.co/relatoria/2009/T-520A-09.htm. Corte Constitucional, Sentencia T-458/10, 15 de junio de 2010. Magistrado ponente Luis Ernesto Vargas-Silva. Disponible en: http://www.corteconstitucional.gov.co/relatoria/2010/t-458-10.htm

16 A tal conclusión se llega luego de observar las consideraciones de algunas jurisprudencias del máximo órgano de la jurisdicción ordinaria en asuntos penales. Corte Suprema de Justicia, Sala Penal, Sentencia de Casación, 17 de noviembre de 2009. Proceso 32183. Magistrado ponente Yesid Ramírez-Bastidas. Disponible en: http://190.24.134.69/sentencias/penal/2009/dr.yesid\%20 ram\%C3\%ADrez\%20bastidas/noviembre/32183(17-11-09).doc. Corte Suprema de Justicia, Sala Penal, Sentencia de Casación, 3 de diciembre de 2009. Proceso 32672. Disponible en: http://190.24.134.69/sentencias/penal/2009/dr.yesid\%20ram\%C3\%ADrez $\% 20$ bastidas/diciembre/32672(03-12-09).doc. Corte Suprema de Justicia, Sala Penal, Sentencia de Casación, 10 de marzo de 2010. Proceso 32868. Magistrado ponente Sigifredo Espinosa-Pérez. Disponible en: $\mathrm{http} / / / \mathrm{www}$. cispa.gov.co/index.php?option=com_content \&view=article\&id=842\&Itemid=73. Corte Suprema de Justicia, Sala Penal, Sentencia de Casación, 17 de marzo de 2010. Proceso 32829. Magistrado ponente Sigifredo Espinosa-Pérez. Disponible en: http://190.24.134.69/ sentencias/penal/2010/dr.sigifredo $\% 20$ espinosa $\% 20$ p $\%$ C3\%A9rez/marzo/32829(17-03-10).doc

17 Corte Constitucional, Sentencia T-821 de 2007, 5 de octubre de 2007. Magistrado ponente Catalina Botero-Marino. Disponible en: http://www.corteconstitucional.gov.co/ relatoria/2007/T-821-07.htm. Corte Constitucional, Sentencia T-441 de 2008, 8 de mayo de 2008. Magistrado ponente Mauricio González-Cuervo. Disponible en: http://www.corteconstitucional.gov.co/relatoria/2008/T-441-08.htm. Corte Constitucional, Sentencia T-045/10, 2 de febrero de 2010. Magistrado ponente María Victoria Calle-Correa. Disponible en: http:// www.corteconstitucional.gov.co/relatoria/2010/t-045-10.htm. Corte Constitucional, Sentencia T-458/10, 15 de junio de 2010. Magistrado ponente Luis Ernesto Vargas-Silva. Disponible en: http://www.corteconstitucional.gov.co/relatoria/2010/t-458-10.htm 
Por último, conviene mencionar que, en buena parte construyendo sobre los desarrollos de la jurisprudencia, el Congreso profirió la Ley 1448 de 2011 o Ley de víctimas. Este estatuto contempla un conjunto de medidas en beneficio de las víctimas de infracciones al Derecho Internacional Humanitario o de violaciones las normas internacionales de Derechos Humanos, ocurridas a partir del 1 de enero de 1985. Así pues, consagró un catálogo amplio de principios y garantías que deben orientar los procesos judiciales y administrativos en los que intervienen este tipo de víctimas; instauró varios instrumentos para la ayuda humanitaria, atención y asistencia a víctimas del conflicto; y estructuró la red de instituciones que estarían a cargo de su implementación.

\section{B. Esfuerzos específicos del Estado colombiano para la protección de víctimas de delitos sexuales}

Conviene advertir que las medidas adoptadas en estas materias se producen en el marco de una tendencia internacional que, en primer lugar, reprocha los atentados contra la libertad, integridad y formación sexuales. En ese sentido, pueden ser mencionados los instrumentos que obligan al Estado a prevenir, investigar y castigar los actos de violencia sexual cometidos en contra de la mujer ${ }^{18}$; y los que han definido la violación sexual como uno de los crímenes contra la humanidad, y bajo algunas condiciones, como un acto de tortura o de genocidio ${ }^{19}$.

Además, la tendencia internacional, subyacente a los esfuerzos locales, ha resaltado el deber de dar a las víctimas un trato digno y respetuoso, y adoptar medidas para reducir los riesgos de victimización secundaria, con ocasión de las diligencias judiciales y de la información sobre los hechos del proceso y la identidad de las víctimas $^{20}$.

18 En ese sentido, pueden ser consultadas la Declaración sobre la Eliminación de la Violencia contra la Mujer; la Convención Interamericana para Prevenir, Sancionar y Erradicar la Violencia contra la Mujer; la Convención sobre la Eliminación de Todas las Formas de Discriminación contra la Mujer; y la Declaración y Plataforma de Acción de Beijing.

19 Por ejemplo, el Estatuto de la Corte Penal Internacional establece que pueden constituir delitos de lesa humanidad la "violación, esclavitud sexual, prostitución forzada, embarazo forzado, esterilización forzada o cualquier otra forma de violencia sexual de gravedad comparable" (artículo 7).

20 Al respecto, puede ser consultada la regla número 70, Principios de la prueba en casos de 
Descendiendo al caso colombiano, en primer lugar, es posible resaltar algunos esfuerzos legislativos a favor de este tipo de víctimas. Así pues, por medio de la Ley 360 de 1997, el Congreso definió que la Fiscalía contaría con Unidades especializadas para la persecución de los delitos contra la integridad sexual (artículo 16). De igual manera, la Ley 360 de 1997 señaló que las víctimas de delitos sexuales estarían amparadas por las siguientes garantías (artículo 15): i) ser tratadas con dignidad, privacidad y respeto durante cualquier actuación con fines médicos, legales o de asistencia social; ii) ser informadas acerca de los procedimientos legales y de los servicios disponibles para atender sus necesidades; y iii) recibir servicios gratuitos de orientación y de tratamiento para la prevención de enfermedades venéreas y para hacer frente a traumas físicos y emocionales.

La Ley 906 de 2004, Código de Procedimiento Penal vigente, en cuanto a la atención a víctimas de delitos sexuales, señaló que las audiencias relacionadas con procedimientos de investigación tienen carácter reservado (artículo 155). Además, estableció que, cuando resulte necesaria la práctica de reconocimiento y exámenes físicos de las víctimas, el procedimiento debe ser adelantado por peritos forenses, en un lugar adecuado y con el consentimiento de la víctima o con orden de juez de control de garantías (artículo 250).

De igual manera, por medio de la Ley 1098 de 2006, en primer lugar, el Congreso profirió normas que afirman la obligación de proteger al menor de las conductas que atenten contra la libertad, integridad y formación sexuales (artículos 20, 39, 41). En segundo lugar, algunas autoridades fueron investidas de funciones para garantizar la atención del menor-víctima de un delito sexual (instituciones educativas, entidades del sistema de seguridad social en salud, comisarios de familia y policía nacional). En tercer lugar, el Código eliminó todos los beneficios y subrogados judiciales o ad-

violencia sexual, de las Reglas de Procedimiento y Prueba de la Corte Penal Internacional, adoptadas por la Asamblea General de los Estados parte del Estatuto de Roma, el 9 de septiembre de 2002. De igual manera, pueden ser examinados los casos 12.350 (contra Bolivia) y 11.565 (contra México) de la Comisión Interamericana de Derechos Humanos, CIDH. Comisión Interamericana De Derechos Humanos, CIDH, Caso 12.350 contra Bolivia. Admisibilidad en: http://www.cidh.oas.org/women/Bolivia12350.htm. Comisión InTERAMER ICANA DE Derechos Humanos, CIDH, Caso 11.565 contra México. Disponible en: https://www.cidh.oas.org/ annualrep/2000sp/CapituloIII/Fondo/Mexico11.565.htm 
ministrativos, salvo en los casos de colaboración efectiva, cuando la víctima sea un menor (artículo 199).

Más adelante, por medio de la Ley 1146 de 2007, el legislador expidió una serie de normas para la prevención de la violencia sexual y atención integral de los niños, niñas y adolescentes abusados sexualmente. Así pues, la Ley estableció el comité interinstitucional consultivo para la prevención de la violencia sexual y atención integral de los niños, niñas y adolescentes víctimas del abuso sexual (artículo 3); y definió que, para hacer frente a este tipo de delitos, el Sistema General en Salud está en la obligación de prestar atención médica de urgencia e integral en salud, mediante profesionales y servicios especializados; y, en consecuencia, debía otorgar al menor atención preferente, adelantar el examen y tratamiento de las enfermedades de transmisión sexual adquiridas, proveer antirretrovirales y realizar la evaluación física y psicológica del niño adolescente (artículo 9).

La misma legislación señaló que los establecimientos educativos deben incluir "elementos que contribuyan a la identificación temprana, prevención, autoprotección, detección y denuncia del abuso sexual..." (artículo 11). Además, instauró la obligación, para los establecimientos de educación media y superior, de incluir una cátedra de educación para la sexualidad, impartida por profesionales debidamente capacitados (artículos 13 y 14).

La Ley 1448 de 2011, por medio de la cual fueron dictadas medidas de atención, asistencia y reparación integral a las víctimas del conflicto armado interno, estableció que la práctica probatoria debe estar orientada por las siguientes reglas, en los casos en que se investiguen delitos que involucren violencia sexual (artículo 38): i) cuando se invoque el consentimiento, como justificación del acto sexual, debe acreditarse la capacidad y libertad de la víctima $\mathrm{y}$, en todo caso, dicho consentimiento no puede ser tácito; ii) la credibilidad de la víctima o de un testigo no puede inferirse de sus comportamientos sexuales anteriores o posteriores y, de hecho, el juez no admitirá pruebas que versen sobre la temática en comento.

En adición a lo anterior, la Ley 1448 de 2011 definió que el juez o magistrado que conozca del proceso puede solicitar medidas especiales orientadas a facilitar el testimonio de la víctima (artículo 41); así como decretar que el testimonio de la víctima sea recibido 
con acompañamiento de personal experto en situaciones traumáticas (artículo 42).

Por último, en cuanto a la legislación, mediante la Ley 1652 de 2013, el Congreso reguló las entrevistas y testimonios en procesos penales de niños y adolescentes víctimas de delitos contra la libertad, integridad y formación sexuales. Esta legislación definió que este tipo de declaraciones deben ser adelantadas por personal especializado del Cuerpo Técnico de Investigación de la Fiscalía, previa revisión del cuestionario por parte del defensor de familia y en un espacio físico acondicionado con los implementos adecuados a la edad y etapa evolutiva de la víctima. Además, aclaró que, en principio, durante la investigación, la víctima solo será entrevistada una vez.

Por otro lado, en la jurisprudencia también es posible encontrar pronunciamientos estatales que favorecen los derechos de las víctimas de delitos sexuales. En ese sentido, mediante la sentencia T-554/0321, la Corte advirtió la existencia de una serie de deberes positivos y negativos de las autoridades judiciales en la investigación y juzgamiento de delitos sexuales cometidos contra menores de edad: los deberes positivos implican la obligación de no actuar de manera ofensiva o discriminatoria (considerando la situación de indefensión en la cual se encuentra); al tiempo que los deberes negativos conminan a las autoridades a tener una particular diligencia a lo largo del proceso penal, al momento de buscar la forma de proteger integralmente al menor.

Partiendo de los referidos deberes, la sentencia presentó las siguientes reglas para la investigación y juzgamiento de delitos sexuales, que tengan a un menor por víctima: i) las autoridades penales están obligadas a informar de la actuación al defensor de familia y al Instituto Colombiano de Bienestar Familiar, ICBF; ii) los funcionarios judiciales deben emplear todos los poderes que estén a su alcance, para hacerse de los medios probatorios que resulten necesarios; iii) los funcionarios solo pueden apelar al principio del in dubio pro reo, luego de haber adelantado una investigación realmente exhaustiva; iv) cada prueba en la que el

21 Esta providencia es reiterada por la sentencia T-458 de 2007. Corte Constitucional, Sentencia T-458/07, 15 de junio de 2007. Magistrado ponente Luis Ernesto Vargas-Silva. Disponible en: http://www.corteconstitucional.gov.co/relatoria/2007/T-458-07.htm 
menor intervenga debe ser realizada de forma tal que respete su dignidad; v) la prueba indiciaria debe cobrar especial relevancia, pues estas infracciones suelen producirse en espacios sustraídos a la observación de testigos; vi) la declaración de la víctima debe constituir una prueba esencial; y vii) el Ministerio Público debe actuar como directo encargado de velar por el cumplimiento de los deberes positivos y negativos.

Más adelante, mediante la sentencia T-453 de 2005, la Corte Constitucional advirtió una tendencia creciente hacia la protección de las víctimas de delitos sexuales dentro del proceso penal y, partiendo de ella, reconoció los siguientes derechos: i) a que se adopten medidas para evitar injerencias innecesarias en la vida íntima de la víctima; ii) a solicitar a las autoridades judiciales que se abstengan de ordenar la práctica de pruebas o excluyan las ya practicadas que conlleven una intromisión innecesaria, o desproporcionada de su derecho a la intimidad; y iii) a que se entienda que no hay consentimiento real y libre de presiones, por la simple ausencia de rechazo físico o de expresiones que lo exterioricen.

Por su parte, en la sentencia T-078 de 2010, la Corte hizo suyas las consideraciones de investigaciones científicas en las que se advierte que "la mayoría de los niños poseen la capacidad moral y cognitiva de dar su testimonio en los tribunales...". Así mismo, el pronunciamiento advierte que, para evitar la revictimización del niño y para garantizar una adecuada reconstrucción de lo sucedido, es preciso acudir a la exploración psicológica.

De igual manera, en la jurisprudencia de la Sala de Casación Penal de la Corte Suprema de Justicia es posible encontrar diversas consideraciones, encaminadas a armonizar el proceso penal con la dignidad del menor-víctima de un delito sexual:

- Es legítimo que el juez penal decida prescindir del testimonio del menor o recaudarlo fuera de la sala de audiencias, para evitar su revictimización ${ }^{22}$.

- El hecho que solo se cuente en la actuación con el testimonio del menor, no impide la emisión de un fallo condenatorio ${ }^{23}$.

22 Cfr. Corte Suprema de Justicia, Sala de Casación Penal, Sentencia del 30 de marzo de 2006. Proceso 24468. Magistrado ponente Édgar Lombana-Trujillo. Disponible en: http://www. cispa.gov.co/index.php?option=com_content $\&$ view $=$ article $\&$ id $=842 \&$ Itemid $=73$

23 Cfr. Corte Suprema de Justicia, Sala de Casación Penal, Sentencia del 19 de enero de 2011. Proceso 30073. Magistrado ponente Fernando Alberto Castro-Caballero. Disponible en: 
- El testimonio del menor no pierde credibilidad por el solo hecho de que no cuente con todas las facultades de discernimiento ${ }^{24}$.

- La declaración de un pariente cercano al menor víctima, como su madre, no constituye prueba de referencia ${ }^{25}$.

- Para evitar la revictimización del menor, el juez podría dar efectos probatorios a las entrevistas rendidas por él con anterioridad al juicio ${ }^{26}$.

- Cuando la víctima es menor de edad y no puede darse a entender por sí misma, los parientes pueden contextualizar en juicio su declaración ${ }^{27}$.

- El juez debe velar para que la víctima menor de edad se encuentre asistida por un profesional que le haga comprensible el procedimiento judicial, y la mantenga fuera de la presencia del agresor ${ }^{28}$.

Con todo, es preciso advertir que la jurisprudencia, tanto de la Sala de Casación Penal, como de la Corte Suprema de Justicia, no ha limitado la protección a las víctimas de delitos sexuales, en atención a su edad. En ese sentido, se ha advertido que, en cualquier caso, es impertinente e ilegal pretender la práctica de pruebas que puedan resultar lesivas de la dignidad de la víctima, en cuanto apuntan a averiguar aspectos como su vida sexual (con anterioridad al punible) o sus condiciones personales y morales ${ }^{29}$.

De igual manera, en relación con los exámenes médicos que deben ser practicados a la víctima, en el marco de la investigación de

http://www.leyex.info/juris/SentenciaCsjsp30073.pdf

24 Cfr. Corte Suprema de Justicia, Sala de Casación Penal, Sentencia del 26 de enero de 2006. Proceso 23706. Magistrado ponente Mariana Pulido de Barón. Disponible en: http://www. cispa.gov.co/index.php?option $=$ com_content $\&$ view $=$ article $\&$ id $=842 \&$ Itemid $=73$

25 Cfr. Corte Suprema de Justicia, Sala de Casación Penal, Sentencia del 3 de febrero de 2010. Proceso 30612. Magistrado ponente Jorge Luis Quintero-Milanés. Disponible en: http://www. cispa.gov.co/index.php?option $=$ com_content $\& v i e w=$ article \&id $=842 \&$ Itemid $=73$

26 Cfr. Corte Suprema de Justicia, Sala de Casación Penal, Sentencia del 10 de marzo de 2010. Proceso 32868. Magistrado ponente Sigifredo Espinosa-Pérez. Disponible en: http://www. cispa.gov.co/index.php?option $=$ com_content $\& v i e w=$ article \&id $=842 \& I t e m i d=73$

27 Cfr. Corte Suprema de Justicia, Sala de Casación Penal, Sentencia del 9 de diciembre de 2010. Proceso 34434. Magistrado ponente Sigifredo Espinosa-Pérez. Disponible en: http://www. cispa.gov.co/index.php?option=com_content $\&$ view $=$ article \&id $=842 \&$ Itemid $=73$

28 Cfr. Corte Suprema de Justicia, Sala de Casación Penal, Sentencia del 15 de febrero de 2012. Proceso 37108. Magistrado ponente María del Rosario González-Muñoz. Disponible en: $\mathrm{http} / / / \mathrm{www}$. cispa.gov.co/index.php?option=com_content\&view $=$ article\&id=842\&Itemid=73

29 Corte Suprema de Justicia, Sala de Casación Penal, Sentencia del 23 de marzo de 2011. Proceso 30566. Magistrado ponente José Leonidas Bustos-Martínez. Disponible en: http://www.cispa. gov.co/index.php?option $=$ com_content \&view $=$ article\&id=842\&Itemid $=73$ 
agresiones sexuales, la jurisprudencia ha presentado los siguientes condicionamientos: i) por regla general, es preciso que la víctima o su representante legal haya dado su consentimiento libre e informado; ii) excepcionalmente, el juez de control de garantías podrá autorizar el examen, a pesar de la negativa de la víctima, cuando haya ponderado si la medida es idónea, necesaria y proporcionada; iii) en ningún caso, se podrá practicar la medida en persona adulta (víctima de un delito sexual) sin su consentimiento informado y libre; y iv) el examen debe tener lugar en condiciones de seguridad, higiene, confiabilidad y humanidad ${ }^{30}$.

\section{C.E1 interés superior de los menores en los procesos de atención a víctimas de delitos sexuales}

Entre los estándares de atención a víctimas de delitos sexuales, se encuentran los que han sido integrados por la Corte Constitucional al bloque de constitucionalidad ${ }^{31}$. Así, la Corte Constitucional ha señalado que la comunidad internacional se ha propuesto una especial protección a los niños para permitirles un crecimiento, desarrollo e integración en la sociedad; como podía inferirse a partir de los siguientes instrumentos: Declaración de Ginebra sobre los Derechos del Niño, Declaración de los Derechos del Niño adoptada por la Asamblea General de las Naciones Unidas, Pacto Internacional de Derechos Económicos, Sociales y Culturales y la Convención sobre los Derechos del Niño ${ }^{32}$.

Respecto al tema de la violencia sexual contra niños y niñas, en posteriores jurisprudencias, la Corte definió que los siguientes instrumentos también formaban parte del bloque de constitucionalidad: Convención Interamericana Sobre Tráfico Internacional de Menores, Convenio Relativo a la Protección del Niño y a la

30 Corte Constitucional, Sentencia C-822 de 2005, 10 de agosto de 2005. Magistrado ponente Manuel José Cepeda-Espinosa. Disponible en: http://www.corteconstitucional.gov.co/ relatoria/2005/c-822-05.htm

31 Corte Constitucional, Sentencia C-191 de 1998, 6 de mayo de 1998. Magistrado ponente Eduardo Cifuentes-Muñoz. Disponible en: http://www.corteconstitucional.gov.co/ relatoria/1998/C-191-98.htm

32 Corte Constitucional, Sentencia C-1068 de 2002, 3 de diciembre de 2002. Magistrado ponente Jaime Araujo-Rentería. Disponible en: http://www.corteconstitucional.gov.co/ relatoria/2002/c-1068-02.htm 
Cooperación en materia de Adopción Internacional y el Código de Infancia y Adolescencia (artículos 18 y 20) ${ }^{33}$.

Partiendo del bloque de constitucionalidad, la jurisprudencia constitucional tiene definido que, en general, el interés superior del menor debe ser prevalente en todas las actuaciones estatales que lo puedan afectar y el Estado debe suministrar todas las medidas de protección que resulten pertinentes y debe poner a su disposición todas las oportunidades y recursos que resulten necesarios para su desarrollo mental, moral, espiritual y social, en condiciones libres, dignas, normales y saludables.

Como anticipaba el presente escrito, al referirse al compromiso del Estado con la protección de víctimas de delitos sexuales, los instrumentos del bloque de constitucionalidad han sido utilizados por la jurisprudencia para ahondar en dos aspectos. En primer lugar, para realzar la capacidad del menor de dar testimonio acerca de los hechos y solicitar a las autoridades judiciales que adelanten una debida valoración sobre el particular, con base en la sana crítica y el examen de las demás pruebas obtenidas (en especial las de carácter indiciario) $)^{34}$. En segundo lugar, el interés superior del menor, contemplado en el bloque de constitucionalidad, ha sido evocado por la jurisprudencia para advertir que los fiscales y funcionarios judiciales deben evitar actuaciones discriminatorias, al tiempo que deben adelantar todas las actuaciones que estén a su alcance, con miras al esclarecimiento de los hechos ${ }^{35}$.

33 Corte Constitucional, Sentencia T-078 de 2010, 11 de febrero de 2010. Magistrado ponente Luis Ernesto Vargas-Silva. Disponible en: http://www.corteconstitucional.gov.co/ relatoria/2010/t-078-10.htm

34 A manera ilustrativa, se podrían consultar las sentencias: Corte Constitucional, Sentencia T-554 de 2003, 10 de julio de 2003. Magistrado ponente Clara Inés Vargas-Hernández. Disponible en: http://www.corteconstitucional.gov.co/relatoria/2003/T-554-03.htm. Corte Constitucional, Sentencia T-408 de 2007, 24 de mayo de 2007. Magistrado ponente Jaime Córdoba-Triviño. Disponible en: http://www.corteconstitucional.gov.co/relatoria/2007/T-408-07. htm. Corte Constitucional, Sentencia T-078 de 2010, 11 de febrero de 2010. Magistrado ponente Luis Ernesto Vargas-Silva. Disponible en: http://www.corteconstitucional.gov.co/ relatoria/2010/t-078-10.htm

35 En ese sentido, se pueden consultar las sentencias: Corte Constitucional, Sentencia T-520A de 2009, 31 de julio de 2009. Magistrado ponente Mauricio González-Cuervo. Disponible en: http://www.corteconstitucional.gov.co/relatoria/2009/T-520A-09.htm. Corte Constitucional, Sentencia T-078 de 2010, 11 de febrero de 2010. Magistrado ponente Luis Ernesto Vargas-Silva. Disponible en: http://www.corteconstitucional.gov.co/relatoria/2010/t-078-10.htm 


\section{LAS ACTIVIDADES DESARROLLADAS EN EL PROYECTO}

La investigación fue abordada desde una metodología cualitativa, que permitiera conceptualizar sobre la realidad, con base en los comportamientos, conocimientos y percepciones de los individuos observados; y que posibilitara la indagación sistemática de los conocimientos y valores compartidos por las personas en contextos particulares. Desde esa perspectiva, fueron observadas las realidades de víctimas, funcionarios, estudiantes y abogados.

Así mismo, se utilizó un diseño metodológico exploratoriodescriptivo, que permitió la representación del proceso de atención a víctimas de delitos sexuales, mediante la recolección y evaluación de datos sobre diversas dimensiones o componentes del fenómeno a investigar. En ese sentido, fue entrevistada una muestra de víctimas que asistieron al Consultorio Jurídico y/o de representantes legales o adultos encargados, entre el 1 de agosto de 2011 y el 31 de julio de 2012. De igual manera, fueron entrevistados fiscales de la Unidad de Delitos Sexuales, jueces de conocimiento, defensores de familia, médicos legistas, funcionarios de los centros zonales del Instituto Colombiano de Bienestar Familiar, ICBF, miembros de algunos consultorios jurídicos (estudiantes y docentes), expertos académicos y otros profesionales en la materia ${ }^{36}$.

En primer lugar, el proyecto buscó obtener datos relevantes sobre los procesos penales por delitos sexuales, que para enero de 2012 estaban activos en el Consultorio Jurídico de la Pontificia Universidad Javeriana; y, en ese sentido, los investigadores elaboraron una matriz de 60 categorías, cuyos expedientes reposan en los archivos del Consultorio Jurídico. La actividad arrojó la siguiente información, partiendo de un universo de 26 casos:

- En el 85\% de los casos, la víctima era de sexo femenino; y, de esa cifra, cerca del 95\% correspondía a niñas menores de 14 años.

36 Para obtener esta información se elaboraron instrumentos de recolección de datos (diarios de campo), que eran documentados por personas que habían asistido a jornadas de entrenamiento y sensibilización sobre la problemática de las víctimas de delitos sexuales en Colombia. También se utilizaron los instrumentos de entrevistas semiestructuradas que fueron validadas por expertos en la materia. Luego de este proceso se realizó un análisis y discusión de los resultados. 
- Solo 4 de las víctimas eran mayores de edad: dos de 24 años, una de 28 y una de 18 , lo que representa el 15,3\% de las víctimas de delitos sexuales. Del $84,7 \%$ restante, el 15,3\% corresponde a menores de 4 años y el 46\% está entre los 4 y los 10 años de edad.

- El 85\% de las víctimas alcanza el nivel escolar de la primaria o está en grados escolares más bajos.

- 12 de las 26 víctimas, casi la mitad, no tenían vínculos con el victimario. Sin embargo, se registraron ocho casos de menores de edad que fueron agredidas por sus padres o padrastros.

- En el $62 \%$ de los casos, el procesado no comparte el mismo techo con la víctima.

- Exceptuando un caso, las víctimas viven con sus familiares, en mayor medida con la madre o la abuela.

- La mayor parte de los casos habían llegado al Consultorio Jurídico durante o después de la audiencia preparatoria. Así, el 50\% de los casos fue recibido para audiencia preparatoria, el 19\% para audiencia de acusación, el 23\% en etapa de juicio, el 3,8\% para sentencia y otro $3,8 \%$ para indagación preliminar.

- Aproximadamente, la mitad de los delitos atendidos corresponden a actos sexuales abusivos en menor de 14 años.

- Aproximadamente, la mitad de la población objeto de estudio había sido representada, al menos, por tres apoderados de víctima una vez asumida la atención por parte del Consultorio Jurídico. La otra mitad ha tenido, al menos, una sustitución.

- No ha sido común la aparición de mecanismos de terminación anormal del proceso (por ejemplo, preacuerdos o principio de oportunidad).

- La mitad de las denuncias conocidas por el Consultorio fueron instauradas en las Unidades de Reacción Inmediata, URI.

- En todos los casos analizados, se solicitó medida de aseguramiento para el procesado. En dos de estos, el juez negó esta medida, lo que ocasionó que el procesado no compareciera al proceso.

En segundo lugar, se llevaron a cabo entrevistas semiestructuradas a profesionales que intervienen en la ruta de atención y a representantes de víctimas atendidas por el Consultorio Jurídico de la Pontificia Universidad Javeriana, con base en cuestionarios 
formulados de forma interdisciplinar, validados por expertos en la materia y que buscaban detectar posibles dificultades en los procesos de las diversas entidades y las necesidades de las víctimas y de las entidades en torno a los procesos de atención. Así pues, fueron entrevistados 10 acudientes de víctimas. De igual manera, en cuanto a los profesionales del proceso de atención, la muestra estuvo constituida de la siguiente manera: tres entrevistas a asociaciones o fundaciones que realizan atención a víctimas de delitos sexuales (Afecto, Creemos en Ti y Casa de la Mujer); dos entrevistas a médicos forenses; dos de centros zonales (Engativá y Barrios Unidos); tres entrevistas a representantes de víctimas (uno de la Universidad Libre y dos de la Universidad Javeriana), entrevistas a tres docentes del área penal (uno de la Universidad Libre, uno de la Universidad del Rosario, uno de la Pontificia Universidad Javeriana). Dos entrevistas a fiscales y jueces, una a funcionarios del Ministerio de Salud y otra a funcionarios de la Secretaría de Salud, dos directores de Centros de Atención a Víctimas de Violencia Intrafamiliar, CAVIF, un personero, una entrevista a un defensor del ICBF y a la coordinadora del convenio Centro de Atención Integral a las Víctimas de Abuso Sexual y el Instituto Colombiano de Bienestar Familiar, CAIVAS-ICBF.

Por último, con el propósito de generar un acercamiento a la realidad que viven las víctimas de delitos sexuales y sus familias, para generar una comprensión más amplia de la función del profesional de la ruta de atención, fueron realizadas dos jornadas dirigidas a estudiantes de Ciencias Jurídicas de la Pontificia Universidad Javeriana.

Cada jornada estuvo constituida por dos sesiones. A la primera jornada, que se realizó el 17 de julio de 2013, asistieron 81 estudiantes; el trabajo consistió en sensibilizar a los estudiantes sobre la problemática, indicarles la importancia de una adecuada representación judicial de las víctimas y los peligros de revictimización en el ejercicio de tal actividad; y la necesidad de visibilizar el trabajo del Consultorio. La segunda jornada, a la que asistieron 41 estudiantes, tuvo lugar el 17 y el 22 de octubre de 2013; en ella, se desarrolló un trabajo que implicó la participación de un facilitador (psicólogo miembro del equipo investigador), que orientó la discusión de los estudiantes alrededor de tres preguntas centrales: 1. 
¿Cuáles son las necesidades de una víctima de abuso sexual infantil?; 2. ¿qué herramientas requieren ustedes para ofrecer una atención que responda a esas necesidades?; 3. ¿cómo se podría realizar un trabajo conjunto entre abogados y psicólogos para responder a las necesidades de la víctima?

\section{PROBLEMÁTICAS JURÍdICAS DETECTADAS EN LA ATENCIÓN A LAS VÍCTIMAS DE DELITOS SEXUALES}

Luego de culminadas las actividades adelantadas en el marco del proyecto, se identificaron problemáticas en la ruta de atención a las víctimas de delitos sexuales, partiendo de los estándares jurídicos que fueron presentados en un acápite anterior.

\section{A. Dificultades relacionadas con la preparación y aptitudes del personal que interviene en el proceso de atención}

El Proyecto reunió elementos para entender que, en general, el personal adscrito a los centros especializados para la atención a víctimas de violencia sexual no ha recibido una capacitación suficiente y que no hay sistemas adecuados para la supervisión de los profesionales que atienden los casos. De igual manera, descendiendo a cada una de las entidades, en los consultorios jurídicos de diferentes universidades, el Proyecto advirtió la falta de disposición en los estudiantes para asistir a los "usuarios" y su desconocimiento (parcial o total) de la finalidad de su intervención en las diferentes etapas del proceso penal, de las posibles formas de reparación y de las instituciones oficiales que podrían contribuir con el restablecimiento de los derechos de las víctimas.

En cuanto a los Centros de Atención de la Fiscalía General de la Nación ${ }^{37}$, además de evidenciar que el número de profesionales destinados a la prestación del servicio se puede ver superado por el volumen de casos, el Proyecto encontró otras dificultades, como el

37 El proyecto estudió los siguientes: Centro de Atención a Víctimas, Centro de Atención e Investigación Integral a las Víctimas de Delitos Sexuales y Centro de Atención a Víctimas de Violencia Intrafamiliar. 
hecho de que el personal de seguridad asume funciones que no son propias de su cargo, la ausencia de un sistema de evaluación para los funcionarios y el hecho de que los estudiantes adscritos como representantes de víctimas no conocen (total o parcialmente) otros centros de atención especializada, la finalidad de su intervención en los procesos penales, las posibles medidas de reparación que pueden ser adoptadas y las posibles formas de revictimización.

El proyecto también reunió información acerca de otras entidades que participan en la ruta de atención a víctimas de delitos sexuales $^{38}$. De nuevo, se evidenciaron una alta carga laboral de los funcionarios (que impide brindar una atención ágil a los usuarios) y cuestionamientos en torno al sistema utilizado para evaluar la asistencia suministrada a la víctima. En adición a lo anterior, también se adelantaron actividades que denotan la existencia de prejuicios en los profesionales y la falta de un enfoque de género.

Al adentrarse en el proceso penal originado por conductas contra la integridad, libertad y formación sexual, el proyecto se dio cuenta de que los servidores públicos involucrados en la investigación no adelantan un seguimiento permanente a la situación de las víctimas (posiblemente en razón a la carga laboral excesiva). En cuanto a la Fiscalía General de la Nación, se allegaron declaraciones en las que se advierte que los diferentes profesionales adscritos a la entidad no suministran información a las víctimas, en los términos del artículo 136 de la Ley 906 de 2004 y de la Sentencia C-454 de 2006. Lo anterior, además de que fueron recibidas denuncias relacionadas con el conocimiento de los delegados acerca del funcionamiento del sistema penal implementado con el Acto legislativo 03 de 2002 y con la falta de preparación de las diligencias.

Por último, en relación con los jueces de conocimiento y a los apoderados de víctimas, las críticas versaron, de manera principal, sobre su intervención durante el incidente de reparación integral. En efecto, se cuestionó su conocimiento acerca de la práctica probatoria y de los conceptos relacionados con los tipos de daños que pueden ser causados a la víctima.

38 En particular, fueron examinadas las siguientes: Defensoría de Familia de Paloquemao, Casa de la Mujer, Creemos en Ti, centros zonales y el Instituto de Medicina Legal. 


\section{B. Dificultades relacionadas con las instalaciones utilizadas para la atención a víctimas}

Del acápite pertinente del presente escrito resulta que, en Colombia, no hay una regulación específica en torno a las condiciones que deben verificarse en las instalaciones utilizadas para la atención a las víctimas de delitos sexuales. No obstante lo anterior, podría sugerirse que, en aras de evitar atentados contra la dignidad y la integridad física y psíquica de las víctimas, es preciso que los ambientes utilizados para la atención no propicien situaciones en las que la víctima se puede sentir agredida por el público en general, por el victimario y, en ocasiones, por los profesionales que prestan el servicio. En adición a lo anterior, el acceso de la víctima a la administración de justicia puede verse truncado cuando acude a espacios en los que no puede tener comunicación efectiva con los servidores públicos.

Pues bien, el proyecto conoció de posibles dificultades relacionadas con las instalaciones utilizadas para la atención a víctimas de delitos sexuales. En ese sentido, en términos generales, en relación con los centros especializados de atención, se evidenció que las locaciones no suministraban la privacidad suficiente. De igual manera, en cuanto a los consultorios jurídicos, en ocasiones, se evidenció que el espacio era utilizado por los estudiantes para actividades ajenas al objeto de la entidad.

En cuanto a las locaciones utilizadas por las organizaciones estatales, se evidenciaron problemas relacionados con el tamaño del lugar, su higiene y orden. Por su parte, se recibieron críticas a los lugares destinados a la administración de justicia por su iluminación y ventilación, y por la falta de control sobre las personas que asisten a las diligencias.

\section{Dificultades relacionadas con la implementación de políticas públicas en la materia}

Aunque el proyecto evidenció el compromiso del Estado colombiano con la protección a las víctimas de delitos sexuales, se advirtieron algunas problemáticas asociadas a las políticas que han sido 
adoptadas para la atención a este tipo de víctimas. Así pues, en cuanto a los centros especializados, se evidenciaron problemáticas relacionadas con la divulgación de protocolos para la atención a víctima de delitos sexuales, con el interés por la implementación de programas de capacitación y con el presupuesto destinado para este tipo de asistencia. Además, en cuanto al proceso penal, el proyecto constató la falta de conocimiento de las víctimas acerca de sus derechos y del funcionamiento de la ruta de atención.

De igual manera, a lo largo de la investigación, se advirtieron inconformidades frente al diseño legislativo vigente, específicamente en lo que se refiere a las medidas de protección a víctimas y a la intervención de la víctima durante la etapa de juicio del proceso penal.

\section{D.Dificultades relacionadas con los servicios prestados a la víctima}

Al analizar los centros de atención especializada, al proyecto le fue manifestado el interés de que las entidades ofrecieran una atención integral (por ejemplo, que la misma institución asista a la víctima en aspectos jurídicos, psicológicos, etc.) y permanente. Además, se advirtió el deseo de que la atención psicológica no se limitara al diagnóstico y al acompañamiento durante las diligencias, sino que trascendiera hacia lo terapéutico; y de que la atención jurídica no estuviera enfocada exclusivamente a la formulación de la denuncia.

De igual manera, se evidenciaron posibles dificultades relacionadas con la continuidad del proceso de atención. Así pues, en los Consultorios Jurídicos, se evidenció cómo un mismo caso es atendido por muchos apoderados; $\mathrm{y}$, en los diferentes centros de atención especializada, se advirtieron la falta de seguimiento a las víctimas que habían sido asistidas y las restricciones al proceso originadas en que la víctima no prestaba colaboración a los profesionales encargados. Igualmente, el proyecto obtuvo información sobre una posible falta de articulación y/o trabajo mancomunado entre las entidades que forman parte de la ruta de atención a víctimas de delitos sexuales (a menudo por desconocimiento sobre el alcance de los servicios prestados por las diversas instituciones). 
Por último, el proyecto recibió constantes referencias a las dificultades relacionadas con la celeridad del proceso de atención. Así pues, en los centros de atención a víctimas, esta problemática se manifiesta en la existencia de varios trámites previos a la prestación del servicio. En el marco del proceso penal, se evidenciaron dilaciones en la investigación y, en la etapa de juicio, el aplazamiento constante de las audiencias.

\section{E.Dificultades relacionadas con la evocación de los hechos}

El proyecto evidenció dificultades relacionadas con la evocación de los hechos que realiza la víctima, a lo largo de la ruta de atención. Así pues, en algunos de los consultorios jurídicos examinados, a fin de conseguir la asesoría del caso, la víctima debe relatar los hechos varias veces, a diferentes personas. Esta problemática se hace extensiva al proceso penal, en el cual además se advirtieron posibles incumplimientos a los parámetros legales para entrevistas y testimonios de menores, y posibles tratos ofensivos provenientes de los abogados y funcionarios que intervienen en las diligencias (en especial cuando se dirigen a la víctima para formular las preguntas del caso).

\section{F. Fundamentos y criterios para la atención jurídica de víctimas de delitos sexuales}

Una vez identificadas las problemáticas que rodean los centros de atención especializada, el proyecto buscó establecer los fundamentos que permitirían definir los criterios para suministrar un servicio adecuado a las víctimas de delitos sexuales. En ese sentido, es posible advertir que, en Colombia, brillan por su ausencia las normas que definan cuál debe ser el alcance de la asistencia jurídica suministrada a las víctimas, cuáles son las aptitudes de las personas que prestan estos servicios $y$, en general, las circunstancias que deben rodear la prestación de la atención jurídica. El artículo 13 de la ley 1448 de 2011 aclaró que la atención a víctima debe estar orientada por un 'principio de enfoque diferencial', en virtud del cual se "...reconoce que hay poblaciones con características parti- 
culares en razón de su edad, género, orientación sexual y situación de discapacidad".

Así pues, los criterios para la asistencia jurídica de las víctimas de delitos sexuales deben ser inferidos, en primer lugar, a partir de las garantías cuya realización debe ser procurada: verdad, justicia y reparación integral (exploradas en acápites anteriores). Posiblemente, en atención al anterior planteamiento, el artículo 9 de la Ley 1448 de 2011 establece que "Las medidas de atención, asistencia y reparación adoptadas por el Estado tendrán la finalidad de contribuir a que las víctimas sobrelleven su sufrimiento y, en la medida de lo posible, al restablecimiento de los derechos que les han sido vulnerados".

En segundo lugar, los criterios deben permitir adaptar esta fase de la atención al contenido de los pronunciamientos nacionales e internacionales que fueron examinados con anterioridad, en relación con las víctimas (en sentido general) y de las víctimas de infracciones a la libertad, la formación y la integridad sexuales. Entre estos pronunciamientos, es sumamente relevante atender a los estándares recogidos por la Asamblea General de la Organización de las Naciones Unidas en la Declaración sobre los principios fundamentales de justicia para las víctimas de delitos y del abuso de poder (Resolución 40/34 del 29 de noviembre de 1985), luego de importantes discusiones transnacionales sobre la víctima y el sistema de administración de justicia ${ }^{39}$.

Igualmente, para inferir los criterios para la atención jurídica de víctimas de delitos sexuales, es oportuno considerar las situaciones que, en la práctica, han sido denunciadas como escenarios de victimización, en especial de victimización secundaria (asunto también abordado en acápites anteriores). En ese sentido, además, resulta de vital importancia considerar los resultados de las actividades adelantadas por el proyecto, en especial aquellas en las cuales las víctimas o sus allegados dieron a conocer sus expectativas e inconformidades frente al sistema de atención vigente.

39 Carlos Rodríguez-Campos, Aspectos históricos y reflexiones sobre la victimología y el derecho victimal en México, Fundación de Victimología en España In Dubio Pro Victima, México, 5 y ss. (s.f.). Disponible en: www.funvic.org/vic_mex.pdf. OrGANIZACIÓN DE LAS NACIONES UNidAs, Declaración sobre los Principios Fundamentales de Justicia para las Víctimas de Delitos y del Abuso de Poder, Resolución 40/34 (29 de noviembre de 1985). Disponible en: http://www2. ohchr.org/spanish/law/delitos.htm 
Por último, las diferentes actividades de investigación evidenciaron la necesidad de humanizar la justicia penal, al realzar el papel protagónico de las víctimas en el proceso y propender por la creación de espacios en los que el dolor sea comprendido y mitigado, al tiempo que la dignidad que le fue arrebatada a la víctima con la comisión del delito sea recuperada. De esta manera, el proyecto condujo a razonar que el proceso de atención debe ser un lugar en el que "...el victimario reconozca su crimen, y restaure el daño causado a las víctimas directas e indirectas, nos exige volver la mirada al otro, a las víctimas y a los victimarios como protagonistas indispensables de una relación ética, una relación de compasión y de responsabilidad, en la que se acojan mutuamente..." ${ }^{\prime 40}$.

Así pues, la atención judicial y extrajudicial prestada a las víctimas de delitos sexuales debe ser caracterizada bajo tres adjetivos ${ }^{41}$. En primer lugar, debe ser comunicativa, en la medida en que las diferentes entidades, por medio de los profesionales, deben propiciar un diálogo que propenda por los postulados de verdad, justicia y reparación. En segundo lugar, la atención debe ser resolutiva y, por esa vía, debe constituir "...un instrumento efectivo para obtener una verdadera solución al conflicto que subyace al delito..."42. Por último, debe ser re-creativa, en el sentido de regresar al pasado y, sobre lo evidenciado, buscar "....construir nuevas relaciones entre las víctimas y los victimarios..."

Ahora, en el caso del Consultorio Jurídico de la Pontificia Universidad Javeriana, es posible presentar los siguientes criterios para concretar los fundamentos en la atención a víctimas de delitos sexuales:

- La voluntad de la víctima debe ser el pilar de la atención. La víctima no puede ser un mero observador de la actuación: es preciso generar espacios constantes para que presente sus opi-

40 John-Carles Mèlich, Filosofía de la finitud, 39, Editorial Herder, Barcelona (2002). Julio ANDrés SAMPEDRo-ARrubla, Las víctimas y el sistema penal: aproximación al proceso penal desde la victimología, Grupo Editorial Ibáñez, Bogotá (2010).

41 Joan-Carles Mèlich, Filosofía de la finitud, 43 y ss., Editorial Herder, Barcelona (2002).

42 Antonio Beristain, Criminología y victimología. Alternativas re-creadoras al delito, Leyer, Bogotá (1998). JoAn-CARles Mèlich, Filosofía de la finitud, 43 y ss., Editorial Herder, Barcelona (2002).

43 Vincenç Fisas, Cultura de paz y gestión de conflictos, Icaria, Barcelona (2006). JoAn-CARLeS Mèlıch, Filosofía de la finitud, 50 y ss. Editorial Herder, Barcelona (2002). 
niones, preocupaciones, inquietudes, expectativas y necesidades particulares.

- Atención debe estar orientada por el enfoque diferencial. Al momento de prestar sus servicios, los profesionales deben atender las circunstancias particulares de la víctima, partiendo de factores como su edad, género, orientación sexual y posibles situaciones de discapacidad.

- Atención jurídica debe ser "integral”. Es preciso que los profesionales encargados de asistir a las víctimas presten todos los servicios de consultoría jurídica y representación judicial que estén a su alcance, con miras a la realización de sus derechos e intereses, y para la determinación de la solución más satisfactoria al conflicto generado por el delito. En ese sentido, es de esperar que la atención jurídica involucre la solución de interrogantes particulares de la víctima, como el suministro de información sobre los derechos que le asisten y sobre aspectos relativos al proceso judicial, el asesoramiento para la interposición de la denuncia y la intervención activa en las diferentes etapas del proceso penal.

- Garantizar la celeridad y continuidad del proceso de atención. Los profesionales a cargo deben adelantar todas las actuaciones para garantizar la pronta y efectiva realización de los derechos de las víctimas. En ese sentido, no solo debe evitar dilaciones en su gestión, sino que debe utilizar los mecanismos pertinentes para hacer frente a los retrasos de otros profesionales. Además, es preciso evitar interrupciones o cambios abruptos en la atención jurídica suministrada, en especial los que puedan generarse por cambios en el profesional encargado o por falta de coordinación con otras personas y entidades que formen parte de la ruta de atención.

- Evitar la evocación de los hechos dañina para la integridad de la víctima. Es preciso que el proceso de atención implique para la víctima la menor cantidad de conversaciones posibles acerca de los hechos constitutivos de delito. De igual manera, los profesionales encargados deben evitar que, en el marco del proceso penal, se produzcan declaraciones innecesarias o que otros actores realicen intervenciones irrespetuosas mientras se produce esta evocación. 
- Profesionales a cargo deben ser 'aptos'. En primer lugar, es preciso que los profesionales a cargo tengan los conocimientos suficientes $y$, en ese sentido, en relación con las víctimas de delitos sexuales, deben estar debidamente capacitados sobre los derechos que les asisten, lo que acontece en las diferentes etapas del proceso penal (específicamente, en lo que se refiere a la intervención de la víctima), las organizaciones a las que pueden dirigirse las víctimas para obtener apoyo, el modo y las condiciones en que pueden pedir protección y las posibles medidas de reparación que pueden ser adoptadas, entre otros aspectos. En segundo lugar, el profesional debe ser entrenado para evitar que su encuentro con la víctima propicie un escenario lesivo para la víctima. Por último, las personas encargadas deben gozar de aptitudes $\mathrm{y}$ calidades personales que permitan una gestión respetuosa y efectiva: inexistencia de prejuicios, habilidades de comunicación apropiadas y disponibilidad de tiempo.

- Sistemas adecuados de supervisión y evaluación. Es preciso que, de manera periódica, las directivas evalúen la idoneidad de los profesionales adscritos y verifiquen el cumplimiento de los objetivos trazados. En caso de resultados negativos, estos deben ser comunicados al profesional encargado, con miras a que sean adoptados los correctivos del caso, con la mayor brevedad posible.

- Instalaciones adecuadas. Las instalaciones deben gozar del tamaño y la luminosidad suficiente, al tiempo que deben ostentar unas condiciones óptimas de higiene y orden. Además, es preciso que los ambientes utilizados para la atención no propicien situaciones en las cuales la víctima se puede sentir agredida por las otras personas que frecuentan la entidad (incluidos los propios profesionales adscritos). Igualmente, las locaciones deben suministrar la privacidad suficiente y no deben ser utilizadas para actividades ajenas al objeto de la entidad. 


\section{CONCLUSIóN}

El Estado colombiano ha reconocido que, en el marco del proceso penal, la víctima debe conseguir la realización de sus derechos de verdad, justicia y reparación. Además, ha adelantado algunos esfuerzos para proteger a las víctimas de los delitos contemplados por el Título IV del Libro II del Código Penal; en especial, frente a algunas hipótesis de victimización secundaria. Por otro lado, también es posible encontrar pronunciamientos judiciales relacionados con los deberes de las autoridades en la investigación y juzgamiento de delitos sexuales cometidos contra menores de edad.

No obstante lo anterior, tras consultar la experiencia de víctimas, servidores públicos que prestan sus servicios en el marco de la ruta de atención a víctimas de delitos sexuales, miembros de algunos consultorios jurídicos (estudiantes y docentes) y expertos académicos, el proyecto evidenció algunas problemáticas desde el punto de vista jurídico. En particular, verificó dificultades relacionadas con la preparación y las aptitudes del personal que interviene en el proceso de atención, con las instalaciones utilizadas, la implementación de políticas públicas en la materia, los servicios prestados a la víctima y la evocación de los hechos que debe adelantar la víctima.

Las problemáticas descritas justifican que los criterios para la atención jurídica de víctimas de delitos sexuales sean reexaminados a la luz de las garantías que han sido reconocidas nacional e internacionalmente, de las situaciones que constituyen escenarios de victimización (en especial de índole secundaria) y de la rehumanización de la justicia penal, a partir de las funciones comunicativa, resolutiva y re-creativa.

En ese sentido, entidades como el Consultorio Jurídico de la Pontificia Universidad Javeriana deben estructurar la asistencia a víctimas de delitos sexuales, a partir de los siguientes criterios: la voluntad de la víctima debe ser el pilar, la atención debe estar orientada por el enfoque diferencial y debe ser integral; es preciso garantizar la celeridad y continuidad del proceso de atención; es necesario evitar una evocación de los hechos dañina para la integridad de la víctima; los profesionales a cargo deben ser aptos; es necesaria la implementación de sistemas adecuados de supervisión y evaluación, y las instalaciones deben ser adecuadas. 


\section{BIBLIOGRAFÍA}

\section{Libros}

Beristain, Antonio, Criminología y victimología. Alternativas re-creadoras al delito, Leyer, Bogotá (1998).

Beristain, Carlos Martín, Diálogos sobre la reparación: experiencias en el Sistema Interamericano de Derechos Humanos, Tomo 1, Instituto Interamericano de Derechos Humanos, IIDH, San José (2008). Disponible en: http://iidh-webserver. iidh.ed.cr/multic/UserFiles/Biblioteca/IIDH/2_2011/6483.pdf

Corporación Humanas, Memorias del Seminario Internacional Judicialización de casos y reparación a mujeres víctimas de delitos de violencia sexual en el marco del conflicto armado, Ediciones Ántropos, Bogotá (2009). Disponible en: http://humanas.org. co/archivos/Memorias_(2).pdf

Díaz-Colorado, Fernando, Las víctimas y la legislación internacional. Victimología. Aproximación psicosocial a las víctimas, Facultad de Psicología, Pontificia Universidad Javeriana, United States Agency for International Development, USAID, Bogotá (2008).

Díaz-Colorado, Fernando, Psicología y Ley, Psicom, Bogotá (2010).

Díaz-Colorado, Fernando, Psicología y Ley. Psicología jurídica, forense, criminológica y victimología, Psicom Editores, Bogotá (2011).

Echeburúa, Enrique \& Guerricaechevarría, Cristina, Abuso sexual en la infancia, víctimas y agresores: un enfoque clínico, Ariel, Barcelona (2000).

Fisas, Vincenç, Cultura de paz y gestión de conflictos, Icaria, Barcelona (2006).

Marchiori, Hilda, Los procesos de victimización. Avances en la asistencia a víctimas, ponencia presentada en el Instituto de Investigaciones Jurídicas, Universidad Nacional Autónoma de México, UNAM, México (2006). Disponible en. http:// www.juridicas.unam.mx/sisjur/penal/pdf/11-534s.pdf

Mèlich, Joan-Carles, Filosofía de la finitud, Editorial Herder, Barcelona (2002).

Oficina de las Naciones Unidas contra la Droga y el Delito, UNODC, La justicia en asuntos concernientes a menores víctimas y testigos de delitos. Ley modelo y comentario, Oficina de las Naciones Unidas contra la Droga y el Delito, UNODC, Fondo de las Naciones Unidas para la Infancia, Unicef (2009). Disponible en: http://www.unodc.org/documents/justice-and-prison-reform/ Justice_in_matters_ES.pdf

Rodríguez-Campos, Carlos, Aspectos históricos y reflexiones sobre la victimología y el derecho victimal en México, Fundación de Victimología en España In Dubio Pro Victima, México (s.f.). Disponible en: www.funvic.org/vic_mex.pdf

Sampedro-Arrubla, Julio Andrés, Las víctimas y el sistema penal: aproximación al proceso penal desde la victimología, Grupo Editorial Ibáñez, Bogotá (2010).

Urra-Portillo, Javier, SOS. Víctima de abusos sexuales, Editorial Pirámide, Madrid (2007). 
WALLER, IRvin, Víctimas del crimen: Haciendo justicia para su apoyo y protección, Manual: La justicia es ciega para las víctimas del crimen, Comité de Enlace de la ONU, Ottawa, Canadá (2006). Disponible en: http://irvinwaller.org/wp-content/uplo ads/2011/02/2003V\%C3\%ADctimas-del-crimenSoros.pdf

\section{Contribuciones en obras colectivas}

Chaparro-Moreno, Liliana, Ley de Justicia y Paz. Se perpetúa la impunidad de los crímenes sexuales y de género cometidos contra las mujeres, en ¿Justicia Desigual? Género y derechos de las víctimas en Colombia, 86-115, Marcela Giraldo, ed., Fondo de Desarrollo de las Naciones Unidas para la Mujer, UNIFEM, ProOffset Editorial, Bogotá (2009).

Messuti, Ana \& Sampedro-Arrubla, Julio Andrés, comps., La administración de justicia en los albores del tercer milenio, Editorial Universidad, Buenos Aires (2001).

\section{Revistas}

Bocanegra-Bayona, Daniel Fernando \& Nieto-Súa, Dary Lucía Esperanza, Modelos de atención a víctimas de delitos: revisión conceptual y observación de la experiencia de tres centros de victimoasistencia en la ciudad de Bogotá, 6 Revista DiversitasPerspectivas en Psicología, 2, 321-338 (2010). Disponible en: http://www.usta. edu.co/otraspaginas/diversitas/doc_pdf/diversitas_10/vol.6no.2/articulo_8.pdf

Carrillo-Urrego, Abelardo, Los delitos sexuales en Colombia, entre el desconcierto y la impunidad, 9 Revista La Sociología en sus Escenarios, 13 (2006). Disponible en: http://aprendeenlinea.udea.edu.co/revistas/index.php/ceo/article/view/1376/1069

SAmpedro-Arrubla, Julio Andrés, Las víctimas del delito en los tiempos del olvido. Una reflexión desde la victimología en torno a la reforma al sistema penal en Colombia, 109 Vniversitas, Pontificia Universidad Javeriana, 95-127 (2005). Disponible en: http://www.redalyc.org/articulo.oa?id=82510903

SAmpedro-Arrubla, Julio Andrés, ¿Quiénes son las víctimas del delito? La redefinición del concepto desde la victimología, 21 Revista Derecho Penal y Criminología, Universidad Externado de Colombia, 67, 151-168 (1999). Disponible en: http:// revistas.uexternado.edu.co/index.php?journal=derpen\&page $=$ article $\& o p=v i e$ w\&path $\% 5 \mathrm{~B} \% 5 \mathrm{D}=1141 \&$ path $\% 5 \mathrm{~B} \% 5 \mathrm{D}=1083$

\section{Tesis}

Capella-Sepúlveda, Claudia \& Miranda, Jennifer, Diseño, implementación y evaluación piloto de una intervención psicoterapéutica grupal para niñas víctimas de abuso sexual, memoria para optar al título de psicólogo, Universidad de Chile, Santiago de Chile (2003).

Miranda-Herrera, Mayra, Victimización secundaria en adolescentes víctimas de delitos sexuales en su paso por el sistema procesal penal en Chile: una aproximación narrativa, Santiago de Chile: Universidad de Chile (2012). Disponible en: http:// 
www.tesis.uchile.cl/tesis/uchile/2012/cs-miranda_m/pdfAmont/cs-miranda_m. pdf

\section{Tratados internacionales}

Organización de Estados Americanos, OEA, Convención Americana de Derechos Humanos, suscrita en la Conferencia Especializada Interamericana sobre Derechos Humanos, San José, Costa Rica (7-22 de noviembre de 1969). Disponible en: http://www.oas.org/dil/esp/tratados_B-32_Convencion_Americana_sobre_ Derechos_Humanos.htm

Organización de Estados Americanos, OEA, Convención Interamericana para Prevenir, Sancionar y Erradicar la Violencia contra la Mujer, suscrita en el vigésimo cuarto período ordinario de sesiones de la Asamblea General, Belén de Pará, Brasil (9 de junio de 1994). Disponible en: http://www.oas.org/juridico/spanish/ tratados/a-61.html

Organización de Estados Americanos, OEA, Convención Interamericana para Prevenir y Sancionar la Tortura, suscrita en el decimoquinto período ordinario de sesiones de la Asamblea General, Cartagena de Indias, Colombia ( 9 de diciembre de 1985). Disponible en: http://www.oas.org/juridico/spanish/tratados/a-51.html

Organización de Estados Americanos, OEA, Convención Interamericana sobre Desaparición Forzada de Personas, adoptada en el vigésimo cuarto período ordinario de sesiones de la Asamblea General, Belém do Pará, Brasil ( 9 de junio de 1994). Disponible en: http://www.oas.org/juridico/spanish/tratados/a-60.html

Organización de Estados Americanos, OEA, Declaración Americana de Derechos y Deberes del Hombre, suscrita en la Novena Conferencia Internacional Americana, Bogotá, Colombia (9 de abril de 1948). Disponible en: http://www. oas.org/es/cidh/mandato/Basicos/declaracion.asp

Organización de las Naciones Unidas, Convención contra la Tortura y Otros Tratos o Penas Crueles, Inhumanos o Degradantes, Resolución 39/46 (10 de diciembre de 1984). Disponible en: http://www2.ohchr.org/spanish/law/cat.htm

Organización de las Naciones Unidas, Convención para la Prevención y la Sanción del Delito de Genocidio, Resolución 260 A (III) (9 de diciembre de 1948). Disponible en: http://www2.ohchr.org/spanish/law/genocidio.htm

Organización de las Naciones Unidas, Convención sobre la Eliminación de Todas las Formas de Discriminación contra la Mujer, Resolución 34/180 (18 de diciembre de 1979). Disponible en: http://www.un.org/womenwatch/daw/cedaw/text/ sconvention.htm

Organización de las Naciones Unidas, Convención sobre los Derechos del Niño, Resolución 44/25 (20 de noviembre de 1989). Disponible en: http://www2.ohchr. org/spanish/law/crc.htm

Organización de las Naciones Unidas, Declaración de los Derechos del Niño adoptada por la Asamblea General de las Naciones Unidas, Resolución 1386 (XIV) (1959). Disponible en: http://www.oas.org/dil/esp/Declaraci $\%$ C3\%B3n $\% 20 \mathrm{de} \% 2010$ s $\% 20$ Derechos $\% 20 \mathrm{del} \% 20 \mathrm{Ni} \% \mathrm{C} 3 \% \mathrm{~B} 10 \% 20$ Republica $\% 20$ Dominicana.pdf 
ORgANiZACIÓN DE LAS NACIONES UnidAs, Declaración sobre la Eliminación de la Violencia contra la Mujer, Resolución 48/104 (20 de diciembre de 1993). Disponible en: http://www2.ohchr.org/spanish/law/mujer_violencia.htm

Organización de las Naciones Unidas, Declaración sobre los Principios Fundamentales de Justicia para las Víctimas de Delitos y del Abuso de Poder, Resolución 40/34 (29 de noviembre de 1985). Disponible en: http://www2.ohchr.org/spanish/law/ delitos.htm

Organización de las Naciones Unidas, Declaración Universal de Derechos Humanos, Resolución 217 A (III), París, Francia (10 de diciembre de 1948). Disponible en: https://www.un.org/es/documents/udhr/

Organización de las Naciones Unidas, Declaración y Plataforma de Acción de Beijing, Cuarta Conferencia Mundial sobre la Mujer, Beijing, China (4-15 de septiembre de 1995). Disponible en: http://www.un.org/womenwatch/daw/beijing/pdf/ BDPfA $\% 20$ S.pdf

Organización de las Naciones Unidas, Estatuto de la Corte Penal Internacional o Estatuto de Roma, Roma, Italia (17 de julio de 1998). Disponible en: http://legal. un.org/icc/statute/spanish/rome_statute(s).pdf

Organización de las Naciones Unidas, Pacto Internacional de Derechos Civiles y Políticos, Resolución 2200 A (XXI) (16 de diciembre de 1966). Disponible en: http://www2.ohchr.org/spanish/law/ccpr.htm

Organización de las Naciones Unidas, Pacto Internacional de Derechos Económicos, Sociales y Culturales, Resolución 2200 A (XXI) (16 de diciembre de 1966). Disponible en: http://www2.ohchr.org/spanish/law/cescr.htm

Organización de las Naciones Unidas, Protocolo I adicional a los Convenios de Ginebra de 1949, relativo a la protección de las víctimas de los conflictos armados internacionales (1977). Disponible en: http://www.icrc.org/spa/resources/ documents/misc/protocolo-i.htm

Sociedad de Naciones, SDN, Declaración de Ginebra sobre los Derechos del Niño, Ginebra, Suiza (1924).

\section{Normatividad internacional}

Corte Penal Internacional, CPI, Reglas de Procedimiento y Prueba. Disponible en: http:// icc-cpi.int/NR/rdonlyres/F1E0AC1C-A3F3-4A3C-B9A7-B3E8B115E886/140167/ Rules_of_procedure_and_Evidence_Spanish.pdf

\section{Normatividad nacional}

Colombia, Acto legislativo 03 de 2002, por el cual se reforma la Constitución Nacional, 45.040 Diario Oficial (19 de diciembre de 2002). Disponible en: http://www. alcaldiabogota.gov.co/sisjur/normas/Norma1.jsp?i=6679

Colombia, Constitución Política (1991). Disponible en: http://www.alcaldiabogota.gov. co/sisjur/normas/Norma1.jsp?i=4125 
Colombia, Ley 360 de 1997, por medio de la cual se modifican algunas normas del título XI del Libro II del Decreto-ley 100 de 1980 (Código Penal), relativo a los delitos contra la libertad y pudor sexuales, y se adiciona el artículo 417 del Decreto 2700 de 1991 (Código Procedimiento Penal) y se dictan otras disposiciones, 42.978 Diario Oficial (11 de febrero de 1997). Disponible en: http://www.secretariasenado.gov. co/senado/basedoc_ant/ley_0360_1997.htm

Colombia, Ley 599 de 2000, por la cual se expide el Código Penal, 44.097 Diario Oficial (24 de julio de 2000). Disponible en: http://www.alcaldiabogota.gov.co/sisjur/ normas/Norma1.jsp?i=6388

Colombia, Ley 906 de 2004, por la cual se expide el Código de Procedimiento Penal, 45.658 Diario Oficial (1 de septiembre de 2004). Disponible en: http://www. secretariasenado.gov.co/senado/basedoc/ley_0906_2004.html

Colombia, Ley 975 de 2005, por la cual se dictan disposiciones para la reincorporación de miembros de grupos armados organizados al margen de la ley, que contribuyan de manera efectiva a la consecución de la paz nacional y se dictan otras disposiciones para acuerdos humanitarios, 45.980 Diario Oficial (25 de julio de 2005). Disponible en: http://www.alcaldiabogota.gov.co/sisjur/normas/Norma1.jsp?i=17161

Colombia, Ley 1098 de 2006, por la cual se expide el Código de la Infancia y la Adolescencia, 46.446 Diario Oficial (8 de noviembre de 2006). Disponible en: http://www.secretariasenado.gov.co/senado/basedoc/ley_1098_2006.html

Colombia, Ley 1142 de 2007, por medio de la cual se reforman parcialmente las Leyes 906 de 2004, 599 de 2000 y 600 de 2000 y se adoptan medidas para la prevención y represión de la actividad delictiva de especial impacto para la convivencia y seguridad ciudadana, 46.673 Diario Oficial (28 de junio de 2007). Disponible en: http://www.secretariasenado.gov.co/senado/basedoc_ant/ley_1142_2007.htm

Colombia, Ley 1146 de 2007, por medio de la cual se expiden normas para la prevención de la violencia sexual y atención integral de los niños, niñas y adolescentes abusados sexualmente, 46.685 Diario Oficial (10 de julio de 2007). Disponible en: http:// www.secretariasenado.gov.co/senado/basedoc_ant/ley_1146_2007.htm

Colombia, Ley 1448 de 2011, por la cual se dictan medidas de atención, asistencia y reparación integral a las víctimas del conflicto armado interno y se dictan otras disposiciones, 48.096 Diario Oficial (10 de junio de 2011). Disponible en: http:// www.secretariasenado.gov.co/senado/basedoc/ley_1448_2011.html

Colombia, Ley 1652 de 2013, por medio de la cual se dictan disposiciones acerca de la entrevista y el testimonio en procesos penales de niños, niñas y adolescentes víctimas de delitos contra la libertad, integridad y formación sexuales, 48.849 Diario Oficial (12 de julio de 2013). Disponible en: http://www.secretariasenado.gov.co/senado/ basedoc/ley_1652_2013.html

\section{Casos de la CIDH}

Comisión Interamericana de Derechos Humanos, CIDH, Caso 11.565 contra México. Disponible en: https://www.cidh.oas.org/annualrep/2000sp/CapituloIII/Fondo/ Mexico11.565.htm

Corte Interamericana de Derechos Humanos, CiDH, Caso 12.350 contra Bolivia. 
Admisibilidad en: http://www.cidh.oas.org/women/Bolivia12350.htm

\section{Jurisprudencia colombiana}

Corte Constitucional, Sentencia C-191 de 1998, 6 de mayo de 1998. Magistrado ponente Eduardo Cifuentes-Muñoz. Disponible en: http://www.corteconstitucional.gov. co/relatoria/1998/C-191-98.htm

Corte Constitucional, Sentencia C-228 de 2002, 3 de abril de 2002. Magistrado ponente Manuel José Cepeda-Espinosa \& Eduardo Montealegre-Lynett. Disponible en: http://corteconstitucional.gov.co/relatoria/2002/C-228-02.htm

Corte Constitucional, Sentencia C-1068 de 2002, 3 de diciembre de 2002. Magistrado ponente Jaime Araujo-Rentería. Disponible en: http://www.corteconstitucional. gov.co/relatoria/2002/c-1068-02.htm

Corte Constitucional, Sentencia C-822 de 2005, 10 de agosto de 2005. Magistrado ponente Manuel José Cepeda-Espinosa. Disponible en: http://www.corteconstitucional. gov.co/relatoria/2005/c-822-05.htm

Corte Constitucional, Sentencia C-1154 de 2005, 15 de noviembre de 2005. Magistrado ponente Manuel José Cepeda-Espinosa. Disponible en: http://www. corteconstitucional.gov.co/relatoria/2005/c-1154-05.htm

Corte Constitucional, Sentencia C-1177 de 2005, 17 de noviembre de 2005. Magistrado ponente Jaime Córdoba-Triviño. Disponible en: http://www.corteconstitucional. gov.co/relatoria/2005/C-1177-05.htm

Corte Constitucional, Sentencia C-370 de 2006, 18 de mayo de 2006. Magistrados ponentes: Manuel José Cepeda-Espinosa, Jaime Córdoba-Triviño, Rodrigo Escobar-Gil, Marco Gerardo Monroy-Cabra, Álvaro Tafur-Galvis \& Clara Inés Vargas-Hernández. Disponible en: http://www.corteconstitucional.gov.co/ relatoria/2006/c-370-06.htm

Corte Constitucional, Sentencia C-454 de 2006, 7 de junio de 2006. Magistrado ponente Jaime Córdoba-Triviño. Disponible en: http://www.corteconstitucional.gov.co/ relatoria/2006/c-454-06.htm

Corte Constitucional, Sentencia C-575 de 2006, 25 de julio de 2006. Magistrado ponente Álvaro Tafur-Galvis. Disponible en: http://www.corteconstitucional.gov.co/ relatoria/2006/c-575-06.htm

Corte Constitucional, Sentencia C-209 de 2007, 21 de marzo de 2007. Magistrado ponente Manuel José Cepeda-Espinosa. Disponible en: http://www.corteconstitucional. gov.co/relatoria/2007/c-209-07.htm

Corte Constitucional, Sentencia C-516 de 2007, 11 de julio de 2007. Magistrado ponente Jaime Córdoba-Triviño. Disponible en: http://www.alcaldiabogota.gov.co/sisjur/ normas/Norma1.jsp?i=27340

Corte Constitucional, Sentencia C-1199 de 2008, 4 de diciembre de 2008. Magistrado ponente Nilson Pinilla-Pinilla. Disponible en: http://www.corteconstitucional. gov.co/relatoria/2008/c-1199-08.htm

Corte Constitucional, Sentencia C-936 de 2010, 23 de noviembre de 2010. 
Magistrado ponente Luis Ernesto Vargas-Silva. Disponible en: http://www. corteconstitucional.gov.co/relatoria/2010/c-936-10.htm

Corte Constitucional, Sentencia C-250 de 2011, 6 de abril de 2011. Magistrado ponente Mauricio González-Cuervo. Disponible en: http://www.corteconstitucional.gov. co/relatoria/2011/c-250-11.htm

Corte Constitucional, Sentencia C-782 de 2012, 10 de octubre de 2012. Magistrado ponente Luis Ernesto Vargas-Silva. Disponible en: http://www.corteconstitucional.gov. co/relatoria/2012/c-782-12.htm

Corte Constitucional, Sentencia C-839 de 2013, 20 de noviembre de 2013. Magistrado ponente Jorge Ignacio Pretelt-Chaljub. Disponible en: http://www. corteconstitucional.gov.co/relatoria/2013/C-839-13.htm

Corte Constitucional, Sentencia T-554 de 2003, 10 de julio de 2003. Magistrado ponente Clara Inés Vargas-Hernández. Disponible en: http://www.corteconstitucional. gov.co/relatoria/2003/T-554-03.htm

Corte Constitucional, Sentencia T-025 de 2004, 22 de enero de 2004. Magistrado ponente Manuel José Cepeda-Espinosa. Disponible en: http://www.corteconstitucional. gov.co/relatoria/2004/T-025-04.htm

Corte Constitucional, Sentencia T-114 de 2004, 12 de febrero de 2004. Magistrado ponente Jaime Córdoba-Triviño. Disponible en: http://www.corteconstitucional. gov.co/relatoria/2004/T-114-04.htm

Corte Constitucional, Sentencia T-453 de 2005, 2 de mayo de 2005. Magistrado ponente Manuel José Cepeda-Espinosa. Disponible en: http://www.corteconstitucional. gov.co/relatoria/2005/t-453-05.htm

Corte Constitucional, Sentencia T-188 de 2007, 15 de marzo de 2007. Magistrado ponente Álvaro-Tafur-Galvis. Disponible en: http://www.corteconstitucional.gov.co/ relatoria/2007/T-188-07.htm

Corte Constitucional, Sentencia T-408 de 2007, 24 de mayo de 2007. Magistrado ponente Jaime Córdoba-Triviño. Disponible en: http://www.corteconstitucional.gov.co/ relatoria/2007/T-408-07.htm

Corte Constitucional, Sentencia T-458 de 2007, 7 de junio de 2007. Magistrado ponente Álvaro-Tafur-Galvis. Disponible en: http://www.corteconstitucional.gov.co/ relatoria/2007/T-458-07.htm

Corte Constitucional, Sentencia T-821 de 2007, 5 de octubre de 2007. Magistrado ponente Catalina Botero-Marino. Disponible en: http://www.corteconstitucional.gov.co/ relatoria/2007/T-821-07.htm

Corte Constitucional, Sentencia T-441 de 2008, 8 de mayo de 2008. Magistrado ponente Mauricio González-Cuervo. Disponible en: http://www.corteconstitucional.gov. co/relatoria/2008/T-441-08.htm

Corte Constitucional, Sentencia T-1135 de 2008, 14 de noviembre de 2007. Magistrado ponente Manuel José Cepeda-Espinosa. Disponible en: http://www. corteconstitucional.gov.co/relatoria/2008/T-1135-08.htm

Corte Constitucional, Sentencia T-520A de 2009, 31 de julio de 2009. Magistrado ponente Mauricio González-Cuervo. Disponible en: http://www.corteconstitucional.gov. 
co/relatoria/2009/T-520A-09.htm

Corte Constitucional, Sentencia T-045 de 2010, 2 de febrero de 2010. Magistrado ponente María Victoria Calle-Correa. Disponible en: http://www.corteconstitucional. gov.co/relatoria/2010/t-045-10.htm

Corte Constitucional, Sentencia T-078 de 2010, 11 de febrero de 2010. Magistrado ponente Luis Ernesto Vargas-Silva. Disponible en: http://www.corteconstitucional.gov. co/relatoria/2010/t-078-10.htm

Corte Constitucional, Sentencia T-458/10, 15 de junio de 2010. Magistrado ponente Luis Ernesto Vargas-Silva. Disponible en: http://www.corteconstitucional.gov. co/relatoria/2010/t-458-10.htm

Corte Suprema de Justicia, Sala de Casación Penal, Sentencia del 26 de enero de 2006. Proceso 23706. Magistrado ponente Mariana Pulido de Barón. Disponible en: $\mathrm{http}: / / \mathrm{ww}$ w.cispa.gov.co/index.php?option $=$ com_content $\& v i e w=\operatorname{article} \& \mathrm{id}=8$ 42\&Itemid $=73$

Corte Suprema de Justicia, Sala de Casación Penal, Sentencia del 30 de marzo de 2006. Proceso 24468. Magistrado ponente Édgar Lombana-Trujillo. Disponible en: http://www.cispa.gov.co/index.php?option=com_content $\&$ view $=$ article $\&$ id $=8$ $42 \&$ Itemid $=73$

Corte Suprema de Justicia, Sala de Casación Penal, Sentencia del 3 de febrero de 2010. Proceso 30612. Magistrado ponente Jorge Luis Quintero-Milanés. Disponible en: http://www.cispa.gov.co/index.php?option=com_content\&view=article\&id $=842 \&$ Itemid $=73$

Corte Suprema de Justicia, Sala de Casación Penal, Sentencia del 10 de marzo de 2010. Proceso 32868. Magistrado ponente Sigifredo Espinosa-Pérez. Disponible en: http://www.cispa.gov.co/index.php?option $=$ com_content $\& v i e w=\operatorname{article} \& i d=8$ 42\&Itemid $=73$

Corte Suprema de Justicia, Sala de Casación Penal, Sentencia del 9 de diciembre de 2010. Proceso 34434. Magistrado ponente Sigifredo Espinosa-Pérez. Disponible en: http://www.cispa.gov.co/index.php?option=com_content\&view=article\&id $=842 \&$ Itemid $=73$

Corte Suprema de Justicia, Sala de Casación Penal, Sentencia del 19 de enero de 2011. Proceso 30073. Magistrado ponente Fernando Alberto Castro-Caballero. Disponible en: http://www.leyex.info/juris/SentenciaCsjsp30073.pdf

Corte Suprema de Justicia, Sala de Casación Penal, Sentencia del 23 de marzo de 2011. Proceso 30566. Magistrado ponente José Leonidas Bustos-Martínez. Disponible en: http://www.cispa.gov.co/index.php?option=com_content\&view=article\&id $=842$ \&Itemid $=73$

Corte Suprema de Justicia, Sala de Casación Penal, Sentencia del 15 de febrero de 2012. Proceso 37108. Magistrado ponente María del Rosario González-Muñoz. Disponible en: http://www.cispa.gov.co/index.php?option=com_content\&view $=$ article $\&$ id $=842 \&$ Itemid $=73$

Corte Suprema de Justicia, Sala Penal, Sentencia de Casación, 17 de noviembre de 2009. Proceso 32183. Magistrado ponente Yesid Ramírez-Bastidas.

Corte Suprema de Justicia, Sala Penal, Sentencia de Casación, 3 de diciembre de 2009. 
Proceso 32672.

Corte Suprema de Justicia, Sala Penal, Sentencia de Casación, 10 de marzo de 2010. Proceso 32868. Magistrado ponente Sigifredo Espinosa-Pérez.

Corte Suprema de Justicia, Sala Penal, Sentencia de Casación, 17 de marzo de 2010. Proceso 32829. Magistrado ponente Sigifredo Espinosa-Pérez.

\section{Documentos y reportes}

Instituto Interamericano del Niño, la Niña y Adolescentes, INN, Declaración y Programa de Acción, Primer Congreso Mundial contra la Explotación Sexual Comercial de los Niños, Estocolmo, Suecia (27-31 de agosto de 1996). Disponible en: http://www.iin.oea.org/iin/Luciana/Pdf/3.5\%20 EXPLOTACI $\%$ C3\%93N\%20SEXUAL/CONGRESOS $\% 20$ MUNDIALES $\% 20$ DE\%20EXPLOTACION\%20SEXUAL,\%20REVISAR/Primer\%20Congreso $\% 20$ Mundial $\% 20$ contra $\% 201 \mathrm{a} \% 20$ Explotaci $\%$ C3\%B3n $\% 20$ Sexual $\% 20$ Comercial,$\% 20$ Declaraci $\%$ C3 $\%$ B3n $\% 20$ y $\% 20$ Programa $\% 20$ de $\% 20$ Acci $\%$ C3 $\%$ B3n, $\% 20$ espa $\%$ C$3 \%$ B1ol.pdf

\section{Sitios web}

Centros de Atención a Víctimas (2007-2008). http://fgn.fiscalia.gov.co/Fiscalia/archivos/ InformedeGestion/infgesfis07-08.pdf 
